\title{
THE CODEX AND THE COMPUTER AS
}

\section{SELF-REFLEXIVE MACHINES}

\author{
MANUEL PORTELA
}
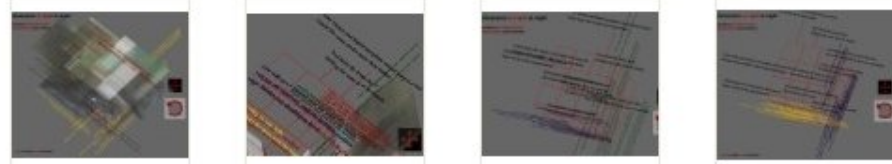

Jason Nelson_dimension Jason Nelson_dimension Jason Nelson_dimension Jason Nelson_dimension s night is night_01(2007) is night is night_02 (2... is night is night_black ... is night is night_black...
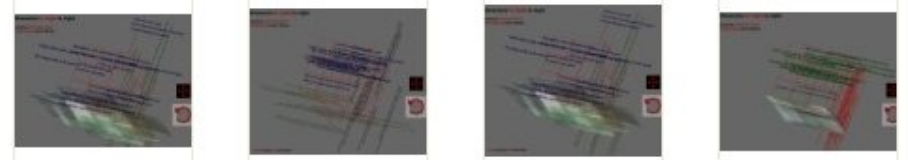

Jason Nelson_dimension Jason Nelson_dimension Jason Nelson_dimension Jason Nelson_dimension is night is night_blue (... is night is night_blueg... is night is night_bluer... is night is night_gree...
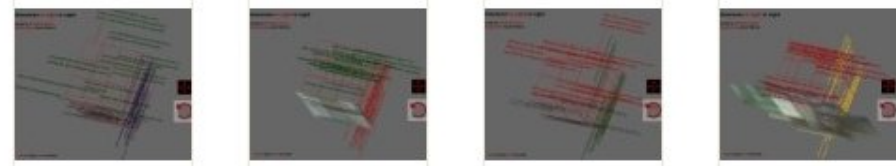

Jason Nelson_dimension Jason Nelson_dimension Jason Nelson_dimension Jason Nelson_dimension is night is night_gree... is night is night_gree... is night is night_redbl... is night is night_redro...
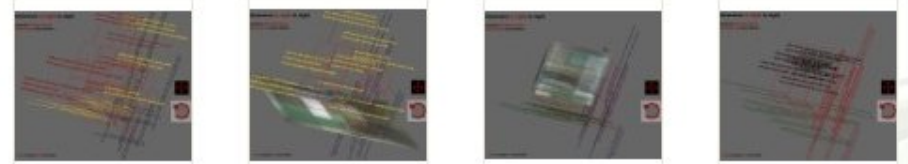

Jason Nelson dimension Jason Nelson dimension Jason Nelson dimension Jason Nelson dimension s night is night_redyel... is night is night_yello... is night is night_room... is night is night_black...

LIÇÃO

PROVAS DE AGREGAÇÃO EM

LÍNGUAS E LITERATURAS

MODERNAS 

NOTA INTRODUTÓRIA

Este documento contém o texto da lição para efeitos de Provas de Agregação na área de Línguas e Literaturas Modernas, de acordo com o estipulado na alínea c) do artigo $5^{\circ}$ do Decreto-Lei 230/2007, de 19 de Junho.

INTRODUCTORY NOTE

This document contains the text of the lecture for 'Provas de Agregação' in the area of Modern Languages and Literatures, in accordance with the provisions set in paragraph c) of Article 5 of Decree-Law 230/2007 of 19 June.

Coimbra, February 24, 2010

Manuel Portela 

TABLE OF CONTENTS

The Codex and the Computer as Self-Reflexive Machines

$\begin{array}{lr}\text { Abstract } & 7\end{array}$

1. On Codices and Computers: A Charting of the Field 8

2. Dis/Assembling the Page: A Physiology of Reading 13

3. Embodying Bookness: Reading as Material Act 16

4. Programmable Signs: A Choreography of Reading 26

APPENDIX: 'Nocturnal Dimensions of the Future' and 'dimension is night is night':

Jason Nelson's Multimodal Recoding of Christine Hume's Poem 39

$\begin{array}{lr}\text { A. Works Cited } & 47\end{array}$

$\begin{array}{ll}\text { B. Works by Johanna Drucker (1972-2006) } & 51\end{array}$

C. Works by Jason Nelson (1999-2008) 53 



\section{The Codex AND the Computer as Self-Reflexive Machines}

Will I ever be able to say, "Today it writes," just like "Today it rains," "Today it is windy"? Only when it will come natural to me to use the verb "write" in the impersonal form will I be able to hope that through me is expressed something less limited than the personality of an individual.

And for the verb "to read"? Will we be able to say, "Today it reads" as we say "Today it rains"? If you think about it, reading is a necessarily individual act, far more than writing. If we assume that writing manages to go beyond the limitations of the author, it will continue to have a meaning only when it is read by a single person and passes through his mental circuits. Only the ability to be read by a given individual proves that what is written shares in the power of writing, a power based on something that goes beyond the individual. The universe will express itself as long as somebody will be able to say, "I read, therefore it writes."

This is the special bliss that I see appear in the reader's face, and which is denied me. Italo Calvino, If on a Winter's Night a Traveller, Translated by W. Weaver. Orlando: Harcourt Brace \& Company, 1981, p. 176.

\section{Abstract}

This lecture looks at self-reflexive mechanisms in codices and computers. It contains a brief introduction to the use of books and computers as expressive media in literature. I want to explore the hypothesis that self-reflexivity in artists' books and in digital poems is useful for understanding the literary dynamics of writing and reading. Self-referential enactments of reading will be shown in works by Johanna Drucker and Jason Nelson. In the selected works, bookness and digitality are foregrounded by a performance of reading that has been formally scripted, in page layout and in computer code. As they travel the sign field of the work, readers experience how their own haptic actions and eye motions co-instantiate the text that they have to read. By means of specific interactions with the material codes of codex and computer, their reading acts become scripted in the writing. This lecture is structured into four parts: (1) On Codices and Computers: A Charting of the Field; (2) Dis/Assembling the Page: A Physiology of Reading; (3) Embodying Bookness: Reading as Material Act; (4) Programmable Signs: A Choreography of Reading. 


\section{On Codices and Computers: A Charting of the Field ${ }^{1}$}

Self-awareness of the medium has been explored to various degrees in codex and computer works. Explicit self-reference is a rhetorical tool for drawing readers' attention to the materialities of communication. It is also a poetical device for activating the expressive function of such materialities. Certain kinds of formal operations require readers to engage with particular modes of bibliographic and computational inscription. Through such aesthetic engagements readers experience how meaning is the effect of a particular embodiment or instantiation of form in a given material medium. This self-reflective instantiation of form heightens the physical and conceptual experience of the mediated nature of meaning, i.e., the fact that meaning is produced by symbolic systems based on material differences. A complex system of differences - linguistic, visual, aural, kinetic - allows for the emergence of form. The self interacts with these material forms by means of specific sensory and perceptual actions that translate into conceptual and discursive relations.

Self-reflectivity as both rhetorical tool and poetical device can be analysed as a pattern of representation and as a performance of the medium. Writing and reading become co-dependent and intertwined as an entangled field maintained by the relations between the semiotic presence of the sign and its interpretative or hermeneutic substitution. While self-reference has often been analysed in terms of the writing act, the rhetorical and poetical self-referential enactment of reading has received less critical attention. In this text, I want to explore print and computer works that selfreflect on the act of reading as a particular semiotic operation and bodily performance. For this I will focus on selected works by book-artist Johanna Drucker and by new media artist Jason Nelson.

\footnotetext{
${ }^{1}$ At a moment when the codex form as the dominant model for the symbolic representation of the world and of human experience seems to be coming to an end, books emerge as one of the most powerful objects for the study of human cultures and societies, both ancient and modern. By means of book history and book studies, the codex recovers its pivotal role as the ultimate machine for knowledge. After witnessing the magic word revealed in religious experience, or the rational word demonstrated in scientific experiment, or the poetic word embodied in literary experience, the book is now an archaeological trace for all kinds of social and cultural transactions. The appearance of the book, described by Lucien Febvre and Henri-Jean Martin in their seminal work L'apparition du livre (1958), became the appearance of the book as an object of study and a privileged image of cultural processes in the research carried out for the past fifty years. If cultural history hypostasized the typographic codex as the materialization of the concept and form of the book, the invention of the electronic page of multiple reinscription reconfigures bibliographic codes and opens up a new documentary ecology which calls for a rethinking of the historicity and materiality of the book. Jerome McGann has written extensively on the relations between codex and computer from a literary and textual studies perspective, cf. Radiant Textuality: Literature after the World Wide Web, New York: Palgrave, 2001. For a major study on the printed book as a knowledge device in early-modern Europe, see Adrian Johns, The Nature of the Book: Print and Knowledge in the Making, Chicago: University of Chicago Press, 1998.
} 
Their work will be placed in the context of self-referential experiments with books and computers.

However, my main purpose is to see how their works shed new light on books and computers by means of self-reflexive operations on the physical and conceptual processing of the work's formal materiality.

Reading acts can be simulated in writing in many ways. They can be verbally represented, but they can also be materially enacted. Verbal reference to reading acts is a conventional feature of many early works of fiction that model the roles of writer/narrator and reader in narrative on the basis of social conversation and social interaction, as happens in the novels of Fielding and Sterne, for instance. $^{2}$ They can be scripted as a print display of constellated signs - in visual texts - or as a computer program that performs iterative operations upon a string of data - in algorithmic works whose display is structured on the basis of topographic patterns or generative syntactic permutations. In both scripts, it is the very motion of linking signs that is being enacted on the page or on the screen. This self-reference to the syntax of reading interferes with the transparency of signifiers and de-naturalizes semantic production. The study of the relation between representing reading and enacting reading, calling upon self-reflective actions on the part of the reader, is what I am referring to as 'scripting reading acts'. Thus 'scripting' means writing both as a specific representation and as a set of instructions for performing specific reading tasks. When translated into computer language, 'scripting' also means writing the code required for automating those representational and performative instructions.

\footnotetext{
${ }^{2}$ Self-reference to writing, reading and publishing as social practices, as well as the description of typographic layout and codex structure as material elements in the production of narrative sustain the continuing tension between plot and discourse in Tristram Shandy. Thus its meta-narrative unfolds as a meta-book, i.e., a sustained self-reflection on its own formal and social materiality as a codex. By 'speaking of my book as a machine' (Vol VII, Chap. I, p. 1), the narrator brings the conditions of production and reception of the printed book, as well as its bibliographic syntax, into focus. Narrative interruption is not only the consequence of digressions, interpolated stories or secondary plots, but also of the foregrounding of the book's internal and external structure as a device for meaning production and communication. In several passages, reflections on narrative continuity bear upon the connection between discourse organization and codex sequence: '--NO doubt, Sir -- there is a whole chapter wanting here -- and a chasm of ten pages made in the book by it -- but the book-binder is neither a fool, or a knave, or a puppy -- nor is the book a jot more imperfect, (at least upon that score) -- but, on the contrary, the book is more perfect and complete by wanting the chapter, than having it, as I shall demonstrate to your reverences in this manner -- I question first by the bye, whether the same experiment might not be made as successfully upon sundry other chapters ---- but there is no end, an' please your reverences, in trying experiments upon chapters -- we have had enough of it -- So there's an end of that matter.' (Volume IV, Chap. XXV, p. 156) The co-determination between discourse and story is further stressed by the co-determination between book and discourse. In other words, Sterne thematizes bibliographic codes as signifying elements in his novel. Laurence Sterne, The Life and Opinions of Tristram Shandy, Gentleman, London, [R. and J. Dodsley, 1761, Volume IV] [T. Becket and P.A. Dehont, 1765, Volume VII], digital edition at http://www.tristramshandyweb.it/ (20 Feb 2010).
} 
The rhetorical and poetical exploration of reading as a motion between signs has to be considered also in relation to conventions and practices associated with specific genres and forms. Major technological changes, like those that introduced print textuality or digital textuality, destabilize conventional forms and genres because they change their formal materiality. The ensuing processes of remediation result in hybrid forms that recombine material features of old media with material features of new media. Media migration and media translation refocus our attention in those material features of the medium that become part of a given signifying system or genre. Because the production of forms in a new medium re-signifies their constitutive elements, such differential functions can be explicitly foregrounded and aesthetically investigated, particularly in transitional moments. Interactivity, for instance, has become a dominant trope for the writing and reading of electronic literature. But the representation of reading acts and appeals to readers' interventions in textual fields has had a continuing presence in print literature as well. ${ }^{3}$

Three lines of research are especially relevant for the problems addressed here. One line is interested in the investigation of the bibliographic materiality of literature, in particular as it performs specific aesthetic and signifying functions. The theoretical and critical analysis of experimental print works and of the artistic use of codex structures in artists' books are important for this investigation (Drucker 1995, 1997, 1999, 2008; Smith 2000; McCaffery \& Nichol 2000; McGann 2002, 2003, 2004). Another productive line of investigation is concerned with the relation between bibliographic and electronic codes, i.e., with the new writing and reading space created by computer processing of visual and aural signs (Bolter [1991] 2001; McGann 1997, 2001; Bolter \& Grusin [1999] 2000; Hayles 2002; Perloff 2006; Shillingsburg 2006; Kirschenbaum 2008; Drucker 2007, 2009; Portela 2009). A third field of inquiry deals with programmable literature and, particularly, with digital works that have been aesthetically engaged with the specifics of digital textuality (Aarseth 1997; Glazier 2002, 2006; Bootz 2006; Cayley 2006; Morris \& Swiss 2006; Peterson 2006; Strickland 2006; Funkhouser 2007; Portela 2006, 2007; Pressman 2007; Seaman 2007; Vesna 2007; Hayles 2006, 2008; Simanowski 2010). Bibliographic works and computer works that self-reflect on their

\footnotetext{
${ }^{3}$ Espen Aarseth has produced the most powerful argument for a new textological episteme to deal with 'the perspective of the text as a material machine, a device capable of manipulating itself as well as the reader' (24). He uses the word 'cybertext' to describe print or electronic works that require reader's interventions in their semiotic fields, and defines those works as 'ergodic' literature (Aarseth 1997: 1-23).
} 
materiality, on the one hand, and theoretical and critical works that deal with those forms of selfreflexivity, on the other, define the creative and research fields briefly charted here.

Of particular interest to my approach are recent critical and theoretical analyses of codex and computer materialities as they are activated by specific aesthetic and formal operations (Kirschenbaum 2008; Hayles 2008; Drucker 2009; Simanowski 2010; Portela 2010). The power of both codex and computer as simulation machines has been widely tested and studied in science, art, and literature. ${ }^{4}$ The networked hypertextual computer, defined by Ted Nelson (1981) as a literary machine ${ }^{5}$, has not only extended many capabilities of the codex, but also revealed the complexities of its particular topology and syntax. The use of books for modelling books, which has been the basis of the critical edition rationale in textual and bibliographic studies since the Renaissance, was challenged in the last two decades by the hypertext rationale (McGann 1997), i.e., by the use of computers for modelling books. Digital representation of literary texts is now a burgeoning (and contested) field, as reflected by many archival and editing projects in electronic media, such as The Rossetti Archive (1993-2008), http://www.rossettiarchive.org/, the Dickinson Electronic Archives (1994-), http://www.emilydickinson.org/, The William Blake Archive (1996-), http://www.blakearchive.org/blake/, or The Walt Whitman Archive (1997-), http://www.whitmanarchive.org/ .

Peter L. Shillingsburg, borrowing from speech-act theory, proposes the concept of 'script act' to account for the multidimensionality of any inscriptional and reading event: 'By script acts I do not mean just those acts involved in writing or creating scripts; I mean every sort of act conducted in relation to written and printed texts, including every act of reproduction and every act of reading'

\footnotetext{
${ }^{4}$ For an excellent compilation of 20th-century reflections on the codex by artists and writers, see $A$ Book of the Book: Some Works \& Projections About the Book \& Writing, edited by Jerome Rothenberg and Steven Clay, New York: Granary Books, 2000. For a broad survey of book technologies, see Nicole Howard, The Book: The Life Story of a Technology. Baltimore: The Johns Hopkins University Press, 2009.

${ }^{5}$ Nelson defined literature as a hypertext in progress: 'A literature is a system of interconnected writings. We do not offer this as our definition, but as a discovered fact. And almost all writing is part of some literature.' (1981). He has argued for the need to go beyond the one-way linking of the web: 'Serious electronic literature (for scholarship, detailed controversy, and detailed collaboration) must support bidirectional and profuse links, which cannot be embedded; and must offer facilities for easily tracking re-use on a principled basis among versions and quotations. Xanalogical literary structure is a unique symmetrical connective system for text (and other separable media elements), with two complementary forms of connection that achieve these functions -survivable deep linkage (content links) and recognizable, visible re-use (transclusion). Both of these are easily implemented by a document model using content lists which reference stabilized media.' Theodor Holm Nelson, 'Xanalogical Structure, Needed Now More than Ever: Parallel Documents, Deep Links to Content, Deep Versioning and Deep Re-Use', in Computing Surveys, 31 (4), December 1999.
} 
(Shillingsburg 2006: 40). The need to edit texts for digital environments has led textual and literary critics to re-examine the bibliographic coding of literary texts in order to produce more accurate models of book structures and books forms. Because codex codes always interact with linguistic codes, digital representations of codex forms are bound to confront the difference between their specific materialities. What the ongoing attempt at representing print texts in digital media has uncovered is not so much the limitations of print, as proclaimed by early apologists of electronic hypertext (Landow [1992, 1997] 2006; Bolter [1991] 2001), but the complexities of the printed book as an inscriptional space. ${ }^{6}$ Projects such as Artists' Books Online (2004-2009) and other speculative investigations concerning the nature of bibliographic interpretation, carried out at the Institute for Advanced Technology in the Humanities at the University of Virginia, have demonstrated just how difficult it is to model the material and conceptual spaces of codex forms in electronic media (Drucker 2009). ${ }^{7}$

\footnotetext{
${ }^{6}$ I reached a similar conclusion when examining a series of digital re-readings of experimental printed poems. Those rereadings, which attempted to recreate visual and concrete texts for a networked hypermedia environment, were performing self-reflective operations already embedded in the original bibliographic coding rather than simply transforming the originals. Reading paths, for instance, were turned into cinematic motions of words that revealed the complexities of the original visual layout as a reading notation. Animation was objectifying the act of reading the print code. While remediating visual texts with its own computer processing codes, animation showed that further unrealized possibilities were contained in print. The dynamics of reading contained in print seems to exceed any particular digital rereading (Portela 2009).

${ }^{7}$ For almost two decades, the rhetoric for promoting e-books has been based upon untested claims and uncritical assumptions about books. This discourse opposes the so-called static, fixed, and finite features of books to the so-called dynamic, interactive, and infinite features of e-books. However, the current migration of the print archive into the digital archive has not confirmed those dichotomies. What markup languages, electronic modelling or emulation of books have shown is the complexity of codex forms rather than their limitations or shortcomings. On the other hand, the virtuality of electronic spaces and the capability for simulation of computer codes do have an enormous potential for the development of new kinds of semiotic and interpretative spaces. Johanna Drucker has investigated this potentiality of virtual spaces: 'The iterative aspects of digital processing, however, are finally making themselves felt in tools that are genuinely interactive and intersubjective and result in material transformation of the text and knowledge produced through the activity they support.' (Drucker 2008: §3) One of my claims in the 'Kinetic Poetry' syllabus is precisely that many digital poems provide that level of critical engagement with iterative processing. Johanna Drucker has also argued in favour of 'speculative computing' as a way of building interpretative interactions into the signifying field, thus claiming a place for subjectivity in computational tools and environments: 'With speculative computing, we moved beyond the instrumental, well-formed, and increasingly standardized business of digital humanities. We used the computer to create aesthetic provocations - visual, verbal, textual results that were surprising and unpredictable.' (Drucker 2009: 19). See also her recent article on the digital reproduction/simulation of contemporary art: 'Making Space: Image Events in an Extreme State', in Cultural Politics: An International Journal, Vol. 4.1 (2008): 25-45.
} 


\section{Dis/Assembling the Page: A Physiology of Reading}

Print constellations and electronic constellations are related not only in terms of their visual materiality, or in terms of their historical genealogy (Funkhouser 2007). Many print and electronic works share a self-reflexive layer of meaning that is useful for understanding reader's interactions with a given sign field. Through analysis of this layer we can point to feedback loops involved in scripting and reading acts. These loops can be materially displayed in the work's surface or they can be conceptually realized through semantic operations, but they are also bodily enacted through eye, hand, and body motions.

The reader of Tristram Shandy, for instance, is periodically reminded of her/his interaction with the writing marks that $\mathrm{s} / \mathrm{he}$ is deciphering. The codex as a narrative organizer and mediator becomes a protagonist of the novel, and the novel is redefined as a book by a continuing reference to its printed codes and to the social codes used for reading it, i.e., its interpretative communities (clergymen, aristocrats, middle classes, women). Hypermediation or the presence of the medium (Bolter \& Grusin 2000) is so pervasive that narrative continuity is repeatedly postponed or interrupted by the evidence of discourse and of its bibliographic materiality. Language and book thus get in the way of narrative and show how the semantic import of what is said is a consequence of how it is being said, of how typography is set on the page, and of how chapters are bound in the codex. As I have argued elsewhere, this self-reference to the materiality of the printed page even uses page-breaks as a narrative intensifier at certain moments (Portela 2000). Sterne is concerned with the physiology of writing and reading in its minute semiotic, bodily, emotional, and social details.

Consider, for instance, the writer-narrator's diagrammatic engraving of the way he has been telling the story in the first five volumes [FIGURE 1]. As a topographic and schematic mapping of Tristram Shandy's narrative journey, this visual representation is also a record of the heterogeneity of writing as an assemblage of diverse and discontinuous signifiers. The irregularities in the lines reflect the writer-narrator's awareness that narrativity is a function of discourse and of the fictional power of language. His desire to find an inner and necessary logic for the story conflicts with his writing 
experience of the myriad possibilities of connecting words and sentences, and thus connecting characters, events, times, and places into a determinable plot. This symbolic productiveness is also the economic and social productiveness of the book as a literary commodity and reading machine. The more the writer writes, the more s/he has to write. The more the reader reads, the more s/he will have to read.
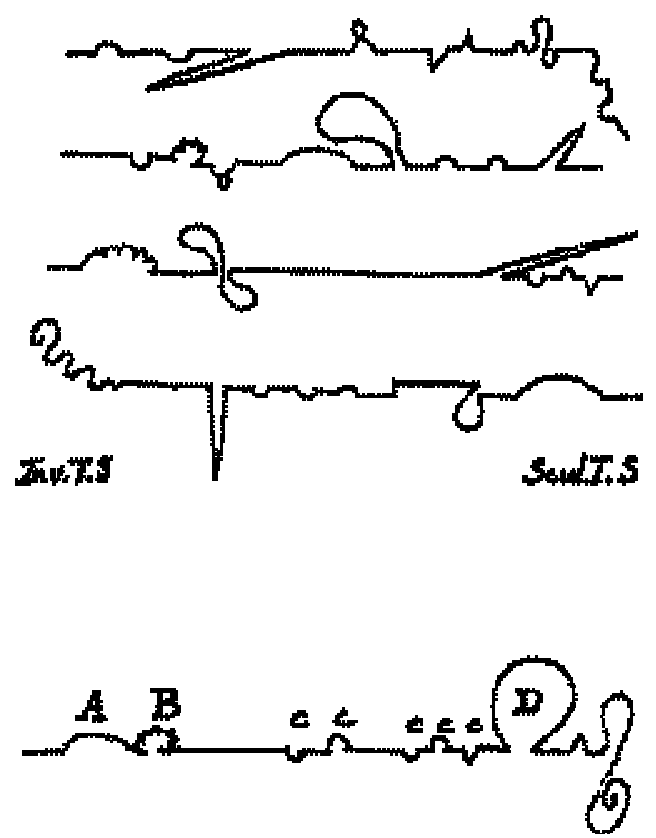

FIGURE 1. The zigzag lines in story-telling according to Tristram Shandy [Volume VI, Chapter XL]. Laurence Sterne, The Life and Opinions of Tristram Shandy, Gentleman, edited by Melvyn and Joan New, Gainesville: University Presses of Florida, [1978]-c1984, Volume 2, pp.570-571.

Likewise, there is an affinity between constellated visual texts as a field of possible paths, on the one hand, and the electronic versions of those print texts as an instantiation of choices that actualize some of those possibilities, on the other. The electronic version becomes a formal embodiment of a reading action on the printed constellation, i.e., a reading course or path. This remediation, in turn, creates a new sign field available for further interpretative acts. Electronic recoding has to make explicit several print features codified by the print layout (such as multicursal paths diagrammatically patterned in visual forms), while creating its own self-reflective devices (Portela 2009). These self-reflective devices may extend self-reference from the visuality of the topographic print layout to the digitality of the new medium itself. Thus the original visual constellation shows itself not as a transparent sign but as a material form that has to be 
experienced as a reading code (i.e., a script or instruction for reading) before any meaning can be produced.

The foregrounding of reading codes that takes place in certain kinds of visual and concrete texts becomes clear when they are treated as storyboards for digital animation. ${ }^{8}$ Animation of constellated works is often a script or set of instructions for reading the work: it actualizes one or more of the potential trajectories and timed sequences contained within its original field of signifiers. The text - which is semi-determined in the sense that its reading syntax admits of several possibilities - is partially co-produced by the way a given reading motion is enacted. This is one of the main self-reflective strategies for scripting reading in books and computers. Formal operations are materially coded in such a way as to make readers aware of the physical, physiological, and cultural processing of signs as a determining component in the material and formal basis for the production of meaning.

Computers have heightened our perception of literature as an exploration of the potentiality contained in signifiers. Considered as automaton, literature could be defined as a symbolic machine for describing and inventing the human through the processing of signifiers. The algorithmic syntax of programming languages has opened up natural language, and other visual and sound systems of signs, to a growing array of recursive and permutational operations. Through automatic processing, the proliferative nature of meaning becomes a material evidence of contemporary digital culture. The author-function struggles with the new disseminative forms of writing and reading that shape the web. While the categories of author and self remain embedded in the very software tools that help to change them, they are also redefined by new forms of human-machine interaction. As human culture is transformed into a huge database of digital objects, artistic and literary practices tend to be increasingly algorithmic, i.e., they depend upon

\footnotetext{
${ }^{8}$ This can be seen when authors themselves adopt the computer, as was the case of E.M. de Melo e Castro, in the 1980s, and of Augusto de Campos, in the 1990s. It is also true for those authors, such as Dick Higgins (1938-1998) and Emmett Williams (1925-2007) whose visual and concrete poems were developed into kinetic texts by others. See E.M de Melo e Castro, Signagens, Lisboa: Universidade Aberta, 1986-89 (VHS); Augusto de Campos, clip-poemas, São Paulo: Perspectiva, 2000 [CD-ROM]; Miekal And, Mesostics for Dick Higgins (1998), http://www.cla.umn.edu/joglars/mesostics/index.html (20 Feb 2010), and after emmet (1998), http://english.umn.edu/joglars/afteremmett/voyage.html (20 Feb 2010); and Po_Ex: Poesia Experimental Portuguesa_Cadernos e Catálogos (2005-2010) http://www.po-ex.net/ (20 Feb 2010).
} 
programming codes that explore the recombinatory possibilities created by the representation of cultural and artistic forms as data sets.

Computers have intensified the cyborg and prosthetic nature of both writing and reading. Semiotic possibilities become the unanticipated result of human-machine intermediation (Hayles 2008) as an open-ended recombination of the modularities of digital media in software culture (Manovich 2001, 2007, 2008). Hermeneutic possibilities are not only determined by historically situated interpretative communities, but also by computer-reader interactions designed to generate new kinds of unanticipated interpretative feedback loops and new social networks in the age of global communications. Interpretative communities now include online communities and the transliteracy practices created and maintained by computer-mediated communication. As computers become ubiquitous machines, social text and technotext are increasingly entangled in our writing and reading practices. What I propose to do next is to analyse this double entanglement in two related domains: I will look at the instantiation of bookness as materialized by a given codex dynamics; and I will analyse self-reflective operations that foreground digitality through specific uses of programming codes.

\section{Embodying Bookness: Reading as Material Act}

Despite containing many highly original creative investigations into the relations between narrative language, typography, and book form, Johanna Drucker's artist's books have received little critical attention. With the help of her own statements about books represented, annotated, and mapped in Artists' Books Online, I will look at her work as an outstanding aesthetic experiment in linking narrativity in language to narrativity in codex-forms. Her poetic exploration of the materiality of the printed codex is based upon a large set of self-reflexive operations. As material investigations of the possibilities of print layout and narrativity, they show an impressive cultural and technical mastery. She has assimilated many print traditions, from modernist and postmodernist poetics to the popular press and the history of printing. Mostly self-produced in limited editions, her works 
cover a wide range of production techniques, including letterpress, off-set, etching, and digital printing. In her stylistic and technical repertoire, one finds collage, drawing, illustration, calligraphy, poetry, fictional prose, and different styles of experimental typography. Typographical design is usually work-specific (and sometimes even page-specific), from typeface choice and paper selection to page layout and binding format.

Her aesthetic work with print - and with written marks in general as visual embodiments of language and signs - has been an overarching concern in her artistic and theoretical work. In the catalogue for an exhibition of her work held at Granary Books, New York City, in June 1994, she offers this overview of her own work:

Books offered a private arena in which to express an ambitious and yet secret, intensely personal, investment of energy. My desire to make books combined a drive to write the world into being, to claim experience through its representation in language, with the desire to make closure and containment, to shut the word within the covers of a finished work held, saved, retained. Two themes run through the works: the first is the exploration of the conventions of narrative prose and the devices by which it orders, sequences, and manipulates events according to its own logic; the second is the use of experimental typography to expand the possibilities of prose beyond the linear format of traditional presentation. (Drucker 1994)

Experiment in typographic presentation and experiment in narrative prose are co-dependent elements in her books. This relation between the visuality of language as embodied in typography and narrativity as an effect of verbal montage is investigated within the full dynamics of codex structure. Page surface, page opening, and page turning provide yet another material dimension in which the relations between typographic design and verbal narrative extend from the visual to the tactile field, i.e., from the $x$ and $y$ axes of the two dimensions of page plane to the $z$ axis of the three dimensions of codex space. A few selected examples are enough to show how the echoes between those three levels draw the reader's attention to the performance of reading as a particular embodiment of a given codex-typography-narrative dynamics. Those echoes reveal the 
book as a machine for creating self-awareness of codex codes through a self-referential rhetoric.

Bookness points to the specificity of their material form as books (i.e., the fact that as a signifying space they cannot be reproduced by or translated into other media), and marks the codex as a signifier that repeatedly attempts to signify itself.

Johanna Drucker's aesthetic engagement with the materiality of the typographic book will be seen in two works: From A to $Z$ (1977) and The Word Made Flesh (1989). ${ }^{9}$ Meta-reference to the material form and modes of production of letterpress printed books is a common feature in several of her works. Most of them are structured on the basis of specific formal relations between typeface, page layout, and book binding. Relations between verbal signs are strongly mediated by the way her works constantly display the dynamics of the printed book, as manifested in the tensions between single page, page opening, and page sequence. She has developed a very personal visual prose in which typographic and bibliographic coding is a major narrative signifier.

From $A$ to $Z$ (1977) - a coded narrative about the community of artists and printers with whom she is working - contains a procedural restriction that makes narrative productivity a function of the individual pieces of type available in the type cases [FIGURE 2]: 'The premise of this book was to take the type in 48 drawers of type, make a text that made sense, and use all of the elements in the fonts once and only once.' (Drucker, $A B O$, project statement). ${ }^{10}$ Thus the frequency of occurrence of any given letter in the text mirrors the quantity of sorts available for upper and lowercase type in each drawer. This reference to the mode of production points to the formal features of type (face, size, style), to its materiality as a metal piece that leaves an inscription mark on paper, and also to its economic nature, as a given amount of available production capital embodied in one of the tools required for printing.

\footnotetext{
${ }^{9}$ Many other works by Johanna Drucker experiment with narrativity, visuality, and bookness. The Experience of the Medium (1978), Bookscape (1988), The History of the/my Wor(I)d(1990) and Narratology (1994), for instance, contain similar material reflections on inscriptions, stories, and writing/reading. For a list of digital facsimiles of her artist's books, see below, pp. 51-52.

${ }^{10}$ A digital facsimile (accompanied by the author's statement and detailed editorial description) is available at Artists' Books Online: http://www.artistsbooksonline.org/works/atoz.xml (19 Jan 2010). 'The type drawers were full and composition, though it often required moving from drawer to drawer, was fairly straightforward for introductory sections. Picking type faces to match character styles and then setting the original "poems" on the recto of the sheets was the next step, and editing was often required as type ran short. The setting of the back sides of each character page required three steps. First, all the sorts left in the case had to be set up and proofed, then they had to be arranged on paper, as in a scrabble game of punning sense. The setting into a final form came after, with pressure to use as many of the sorts as possible.' http://www.artistsbooksonline.org/works/atoz/edition1.xml (19 Jan 2010).
} 


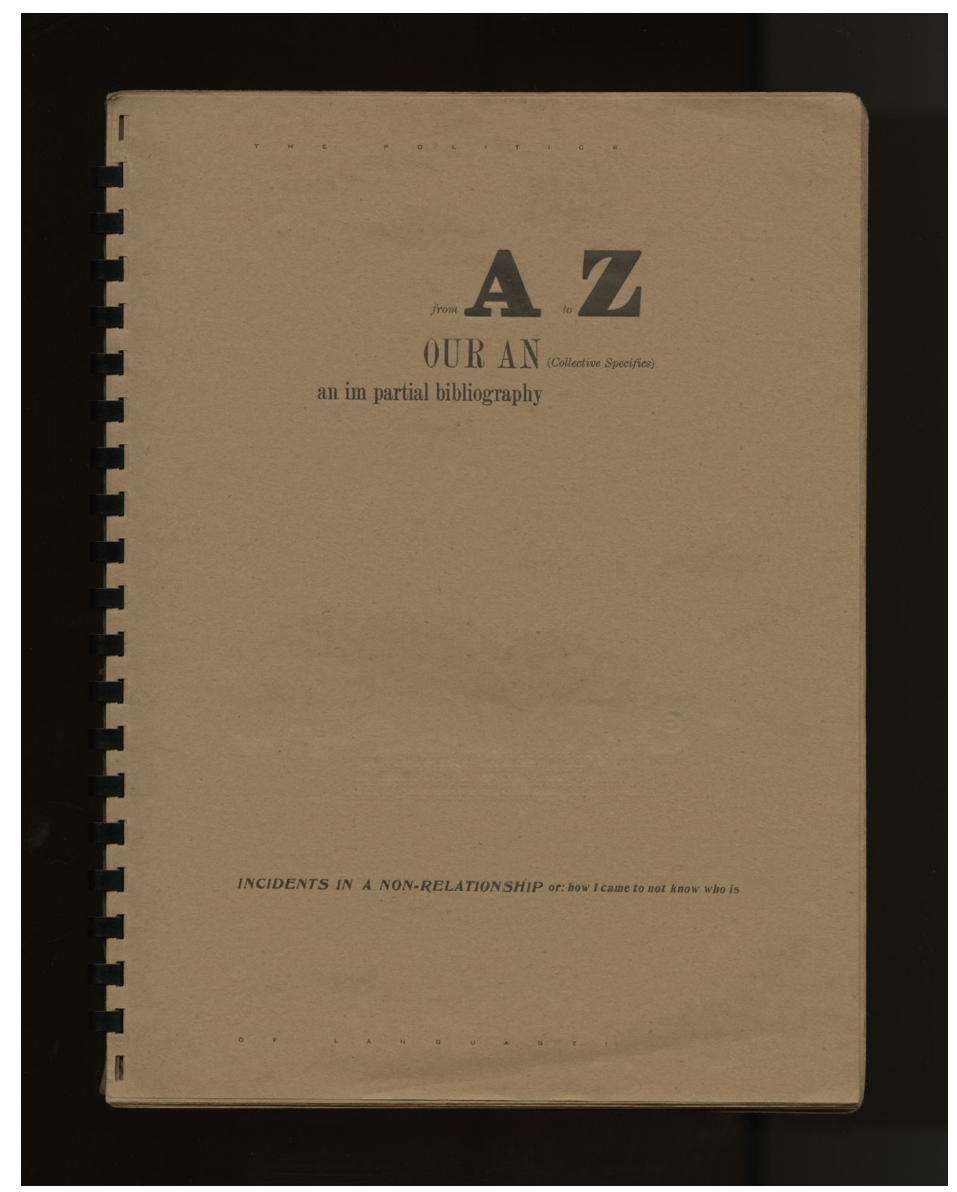

FIGURE 2. Johanna Drucker, From A to Z: Our An (Collective Specifics) an im partial bibliography, Incidents in a Non-Relationship or: how I came to not know who is (1977), titlepage.

Original size: $7.375 \times 12$ inches.

As a procedural work it turns the typographic alphanumeric characters, including punctuation signs and other special type, into one of the content layers of the book. Its self-imposed constraint of using only a limited set of type means that its narrative content has to be adjusted to its typography. Linguistic combinations will be partially determined by typographic possibilities, thus translating the medium back into narrative content and structure. In From $A$ to $Z$, the visual layout, i.e., the topographic organization of the page, the syntax of pages, and the montage of its narrative sequences inscribe the materiality of the mode of production within the text's narrativity. Its exploration of the combinatorial potential of the written alphabet as an extension of the syntactic nature of verbal language is experienced as a fully material encounter with typography as material artefact. 
The generative power of the constraint can be seen, for instance, in the subversion of orthographic spelling, which is either replaced by characters that are partially similar in terms of visual or sound form, or simply omitted and inferred from set sequences (in anticipation of current 'sms' simplified conventions): 'Sum'SORtS (...) WAS, US'D, UP, AND, SUM, WAS, LeFT, OV'R, AND. OF, A, HUNN'RD, COPI'S. ZIS. ON', IZ, NUMB'R :.........' [FIGURE 3]. This principle of simplification eliminates orthographical redundancies and produces readable sequences that recode writing conventions. The act of setting type and the quantification of its economic value as a given number of set pages is sometimes referred to in the verso of several folios. As a personal autobiographic project, From $A$ to $Z$ contains marks of its production at formal, biographical, and economic level.

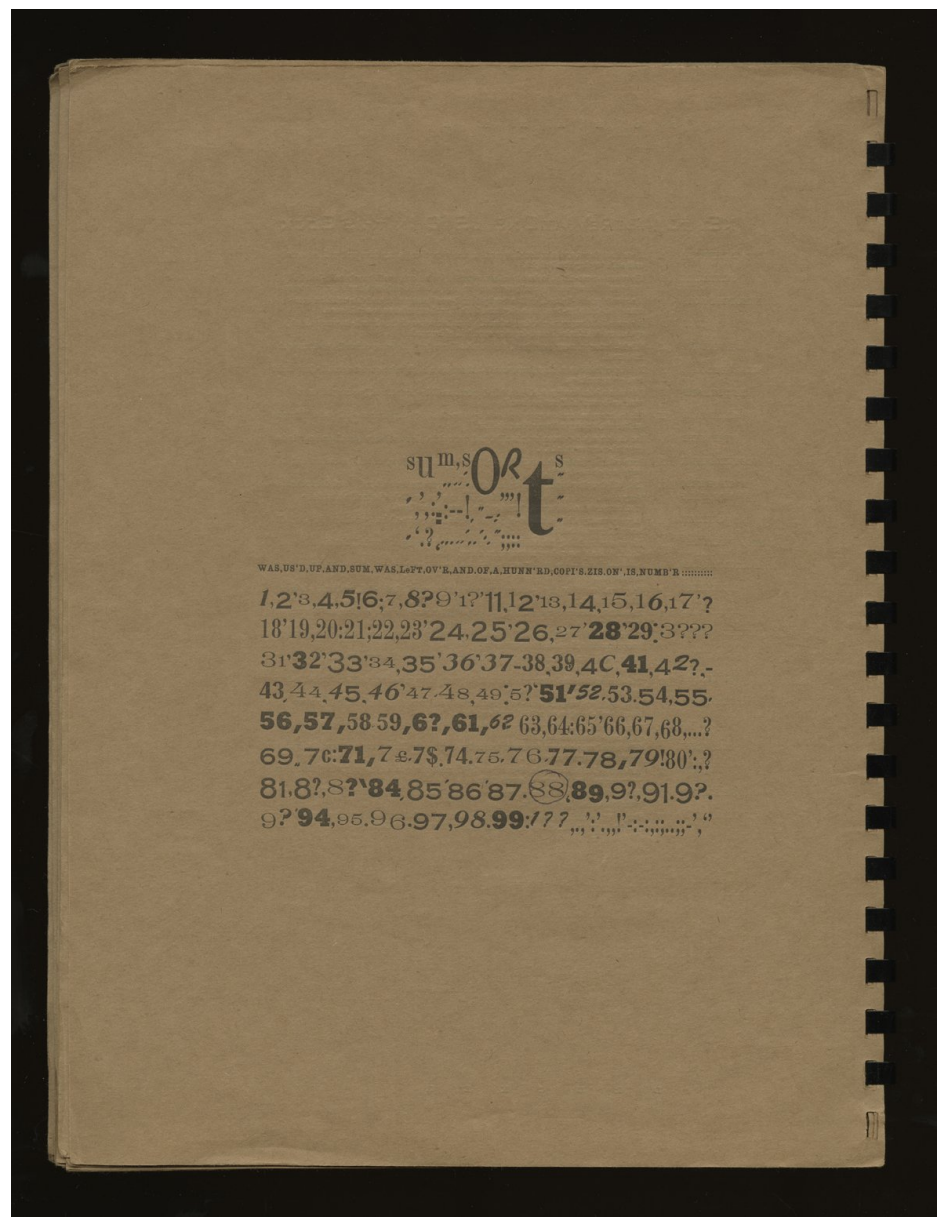

FIGURE 3. Johanna Drucker, From A to Z (1977), colophon, page 66. Original size: $7.375 \times 12$ inches.

The fact that the work contains running marginal notes adds a parodic dimension to its form as a book, mocking its own descriptive pretensions while signalling a particular kind of annotated book - 
the annotated bibliographic list [FIGURE 4]. Because its narrative attempts to describe the relations between the individuals in the print workshop (and particularly an imaginary love "non-relationship" between $A$ and $Z$ ), its reference to the means of production may be said to include the social and affective relations of production. A careful reading of its coded allusions also highlights the power relations that structure the affective and productive positions within this print community. From $A$ to $Z$ narrates the print workshop as a catalogue of typographic types and as a catalogue of human types. The tension between description and self-description never allows the reader to entirely leave the surface of the page. This visual anchorage is the source of recurrent formal echoes between medium and content. Typographic layout and book structure become crucial elements in the work's meaning. Readers become aware of the recodification of spelling and typesetting conventions. Changes are the result of the constraint imposed on the number of fonts, styles and characters available at each stage of composition. The letterpress itself is written into the narrative.

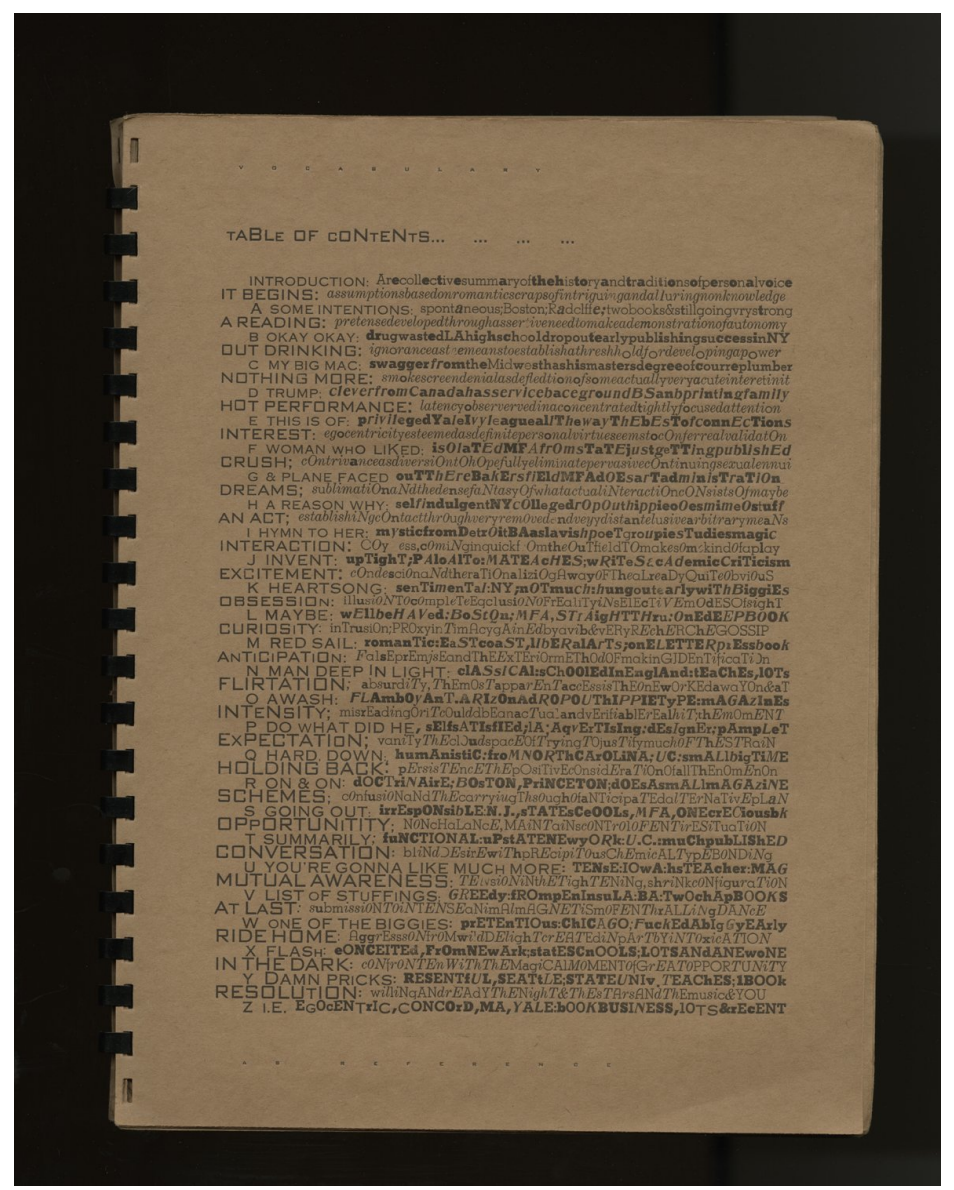

FIGURE 4. Johanna Drucker, From A to Z (1977), Table of Contents, page 05. Original size: $7.375 \times 12$ inches. 
In The Word Made Flesh (1989) the layering of verbal and typographic meaning is equally complex [FIGURE 5]. The text offers several typographic reading paths that superimpose on the page. Paths are created by a basic rectangular grid that governs the arrangement of type on the page. ${ }^{11}$ The use of two print colours (red and black) as well the expressive use of other font properties create two reading paths: a background same-size-capital red text, of which each letter is symmetrically set at the grid's points of intersection; and a foreground varying-size black text that is set over the grid, thus interrupting and breaking the background pattern. Because the foregrounded text uses contrasting type sizes and styles, the result is a dynamic engagement of readers in deciphering words and sentences while moving between the background and foreground plane. This play with the materiality of type forms (font, size, style, kerning, leading, baseline, height, etc.) enacts the meaning of the title in the experience of trying to make sense of words and sentences.

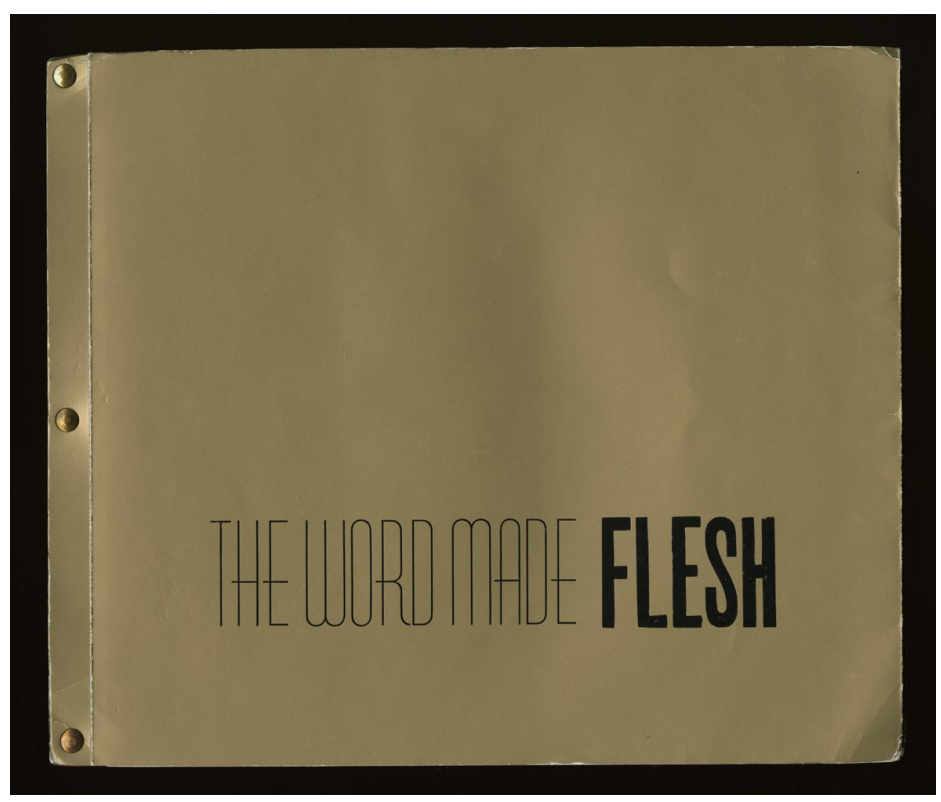

FIGURE 5. Johanna Drucker, The Word Made Flesh (1989), cover.

Original size: 12.6 x 10.6 inches.

The Word Made Flesh further denaturalizes print by combining different fonts, sizes and styles in the same words and sentences. Several words are made to share the same character, which runs across two or more lines, as happens with all the letters in the phrase 'THE WORD MADE

\footnotetext{
${ }^{11}$ This grid has c. 19 (horizontal) $\times 14$ (vertical) character positions on each page, i.e., c. 266 possible positions. Spaces between grid words are sometimes distributed unevenly, which adds to the dynamism within and between the red and black layers.
} 
FLESH' ${ }^{12}$. These sixteen characters (which are in fact 20 , because the ' $T$ ' occurs five times) define diagonal reading trajectories within the basic horizontal/vertical type-setting grid. Large-scale letters become themselves the material centre of this typographic narrative, as they spread across the pages. The tension between letter sequence and letter constellation on each page increases the verbal tension between the lyrical and narrative/reflective threads in this work. ${ }^{13}$ At the same time the reader is forced to pause and consider the particular shape of the letter as if he/she were looking for the type to set the text. Reading becomes a typographic experience because it emulates part of its particular production history. The setting of type is made present in the reading of the text.

Temporality and spatiality inherent in codex structure as a syntactic arrangement of folios and pages is experienced by readers when shifting back and forth between a self-enclosed constellated page and a continuing typographic narrative. Because the title-sentence is written across 20 recto pages ('TTTTTHEWORDMADEFLESH', pp. 7-45), the work suggests a homology between syntactic structures in language and syntactic structures in codex. Page sequence establishes the basic syntax of codex forms, while type variations are a specific occurrence or instance of an abstract system of differences that guarantees the identity and semantic productivity of typography as a semiotic system. The initial sentences of the text echo the Saussurean conceptual dichotomy between langue/parole, and the Chomskian distinction between deep/surface syntactic structures: “A l'interieur de la/du langue/age" (p. 3), "I” (p.5), “I/T” (p. 7), “I/T / LAY / the tongue” (p. 9), “The tongue LIES ON THE TABLE" (p. 11), "The tongue LIES ON THE TABLE / writing, writhing, spelling out THE breath of its efforts in an unseemly desire to be seen / A stick taken up in defense of THE world marks THE struggling back of THE folds of skin" (p. 13 and p. 15). ${ }^{14}$

\footnotetext{
${ }^{12}$ This stylistic feature is called 'paragonnage', i.e., the combination of different sizes of type within the same line or word. Cf. Drucker, http://www.artistsbooksonline.org/works/wmfl/edition1.xml (19 Jan 2010).

${ }^{13}$ In her critical analysis of her own work, Drucker stresses the dialectics between the word-made-flesh and the flesh-made-word: 'This project worked as a book on the strength of the typographic argument. The theme of word made flesh and the counter theme (written in the red copperplate field) of the flesh made word, are so completely integrated into the presentation, and in such an unequivocal, graphically striking manner, that the theoretical issues are rendered explicitly.' Drucker also refers to her page design as a field/figure relationship, stressing the visuality of the ' $T$ ' as an emblem of the cross: '[...] the black texts are meant to "figure" against the red ground, as the images of Christ, a cross, or other devotional images are called out in carmina figurata.' Cf. Drucker, 'Critical Discussion' and 'Detailed Analysis', in http://www.artistsbooksonline.org/works/wmfl/edition1.xml (19 Jan 2010).

${ }^{14}$ The corresponding background red text (which appears for the first time on page 15) reads: 'ALL THE WATERS, ELEMENTS AND PRIMAL FISHES BROKE THROUGH AIR AND AROUND US INTO TONGUES. HOW WAS THE TRACE OF DISPLACEMENT INTO PALE AIR MADE INTO SPEECH BY A BREAKING WAVE OF CHANCE? ALL TH NIGHTS, BROKEN GLAS'.
} 
Drucker is thinking about typography and codex in terms of a system of differences that has a fully syntactic expression. The syntactic recursivity of language is made to mirror the syntactic recursivity of typography as a combination of type units, and of the codex as a combination of page units. The productivity of the recombination of those units is shown through a process of accretion that, at each turning of the leaf, keeps adding new verbal elements to form sentences and new typographic patterns that eventually extend to the full space of the page. The act of being inside language (and inside the printed book as a reliving of the origin of language) is dramatized in the work's generative development from blank page to one character, to a few words, to full sentences, and to an entire discourse. Furthermore, the production of self in language and its inscription within the codex has been objectified in the initial transition between 'l' (p. 5) and 'IT' (p. 7). The codex transubstantiates the word by giving it, as it were, a visual and material existence that seems to give flesh to meaning. The very consciousness of self emerges as a linguistic function, i.e., as a particular product of the empty flesh of signifiers.

In The Word Made Flesh, the incarnation of the word is obtained by self-referring to its typographical layout through a given reading performance. But this embodiment of the word is made to take the flesh of paper as well. The inscriptions of ink on the surface of paper are experienced not just as a series of abstract formal differences that replicate the differential system of language, or a given discourse as a specific cultural and narrative instance of language structures and ideological content. Folios are printed on the recto side of a semi-transparent paper which allows for the following recto page to show through, and also for the recto to be seen from the verso [FIGURE 6 and FIGURE 7]. Instead of a printing error, the printed matter which can be seen from the other side of a leaf projects type and word onto codex space. The typographic layering of the two main reading trajectories extends to the three-dimensionality of leaf and codex. Semitransparency has made paper visible and touchable. Printed words can be experienced not just as inked inscriptions but as paper objects. In The Word Made Flesh type and paper are structural components of the meaning of the text. To read The Word Made Flesh is a renewed optical and tactile relation with its self-consciously crafted printness and bookness.

http://www.artistsbooksonline.org/works/wmfl/imageindex/1.1.1.21.xml (19 Jan 2010). This running text upon language concludes (on page 45): 'SIGNS OF MONUMENTALITY, SUGGESTIONS AND RECONDITIONED BODIES MANIFEST THEMSELVES LONG ENOUGH TO BE RECOGNIZED ACCORDING TO THE DELICATELY NUANCED PACE OF ARTICULATION OF A RAW AND PASSIONATE TONGUE.' http://www.artistsbooksonline.org/works/wmfl/imageindex/1.1.1.51.xml (19 Jan 2010). 


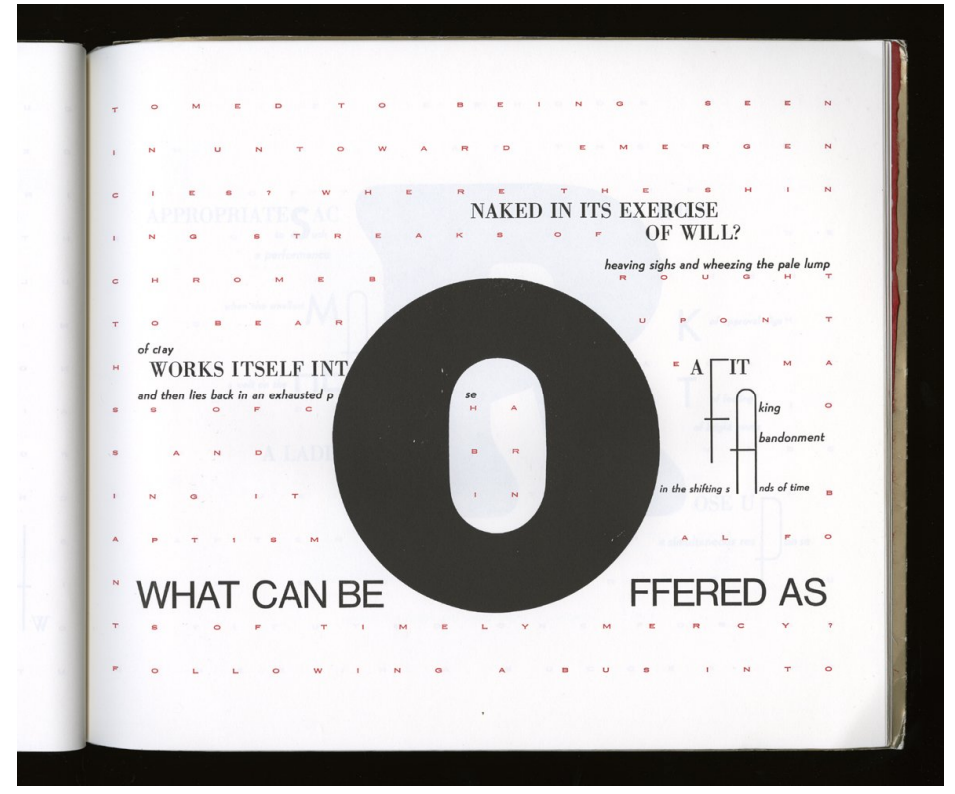

FIGURE 6. Johanna Drucker, The Word Made Flesh (1989), p. 23. Original size: $12.6 \times 10.6$ inches.

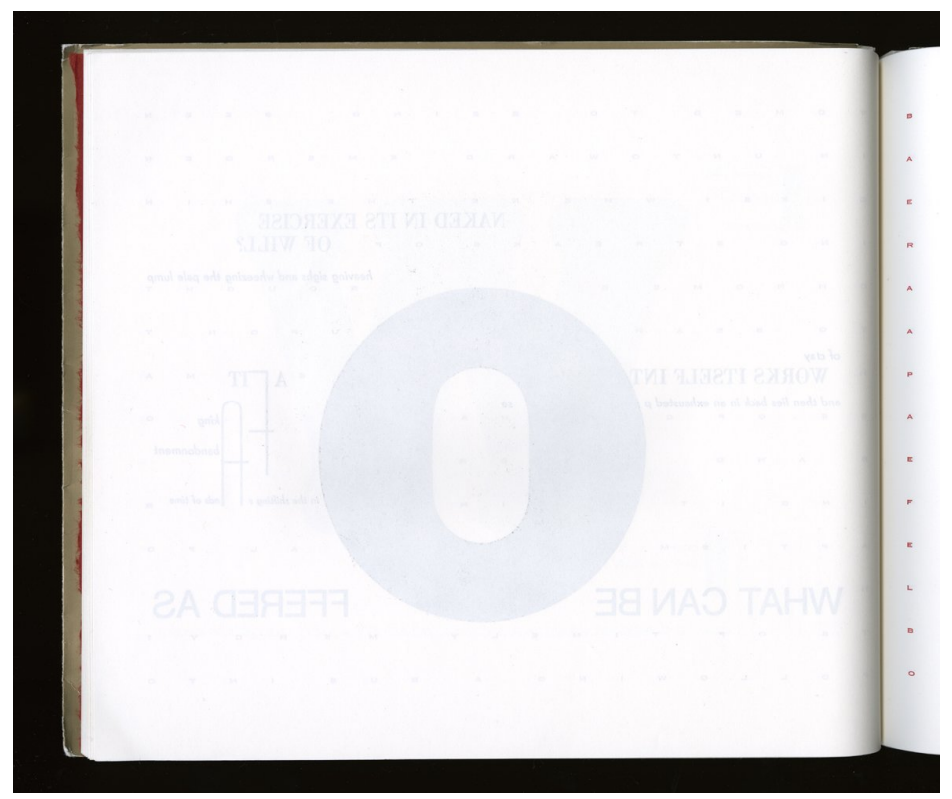

FIGURE 7. Johanna Drucker, The Word Made Flesh (1989), p. 24.

Original size: $12.6 \times 10.6$ inches. 


\section{Programmable Signs: A Choreography of Reading}

The work of Jason Nelson is one of the leading explorations of intermediality and programmability in current digital poetry. He applies algorithmic procedures to visual, kinetic, and sound textualities. In his multimodal works programming is used to reflect on digital materiality, and on the nature of cognitive perception of form and meaning. Random permutations and iterative processes, combined with hypermedia fragmentation, place readers in the midst of a labyrinth of visual and aural signs. Readers have to come to terms with the chaotic and probabilistic nature of algorithmic and machinic processes of meaning production. This experience of indeterminacy challenges the discursive consistency of conventional literary and artistic genres. In Jason Nelson's technotexts, digital technology foregrounds the specificity of its mode of computational and electronic inscription. This foregrounding testifies to his extraordinary formal inventiveness in the aesthetic use of codes and programming tools. He is a database poet who has turned the modularity of computer materiality into one of the structural elements for multicoding his works, which combine drawings, collage, photography, video, words, sounds, etc., in multi-layered and multi-textured compositions. His cybertexts emulate electronic space itself and they redefine the poem as a plaything that reflects upon algorithmic culture and database aesthetics.

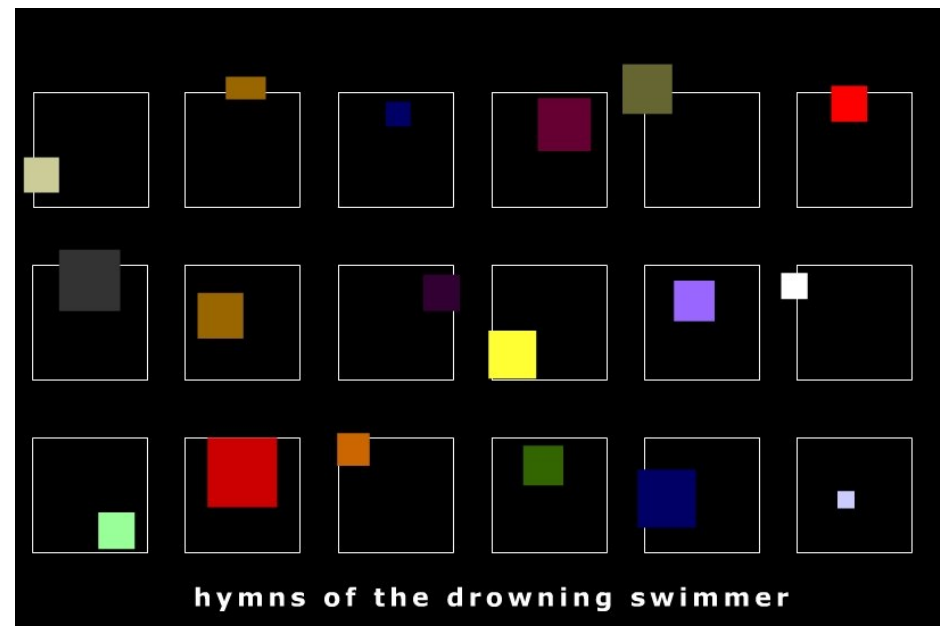

FIGURE 8. Jason Nelson_hymns of the drowning swimmer (2004) [screen capture]. 
His intermedia digital works are a late product of the interaction between writer and computing machines in which programming cannot be thought of as separated from graphic, kinetic or sound display. In hymns of the drowning swimmer $(2004)^{15}$ the reader encounters a complex reticular hypermedia structure. Readers are exposed to this hypermediated space and to the signifying hyperphagia that defines contemporary global communications networks [FIGURE 8]. Semiotic overproduction and multimedia overload are suggested by this sign-saturated work. Its sequences and frames are generated from a randomized collection of fragments, grouped into 18 sections. They are organized in multiple iterations, branches, loops, and redundancies. Because progress and recurrence have to be constructed by the reading self without any clues, reading assumes the figure of the networked labyrinth. Most elements in this work are organized on the basis of looping permutations. These include sound files, video files, graphic icons, drawings, different types of images (drawings, printings), linguistic fragments, and simultaneous layering and patterning of the various elements on the screen. Random numbering of the 18 sequences, absence of any narrative or discursive continuity, very diverse visual patterns, as well as varied biographical, cultural and technological references in each sequence - all of these contribute to the experience of nontotalization, i.e., for the difficulty in stopping the play of/with signifiers. The reader experiences cognitive disorientation as a drowning in the overloaded system of the electronic work.

hymns of the drowning swimmer (2004) combines the hyper-structured and the hyper-fragmentary that may be said to be a defining characteristic of postmodern cybernetic culture. Once the database structure of a work is subject to algorithmic processing the result is a truly recombinant poetics (Seaman 2007), i.e., a poetics of literature as potentiality - a potentiality that projects automated signifiers onto individual consciousness in search for meaning. Bill Seaman's description of subject/object interaction in algorithmic works seems entirely adequate for Jason Nelson's work:

As we explore material in interactive work, meaning arises out of a subject/object unity. The participant draws on past experience and defines his or her own approach to understanding

\footnotetext{
${ }^{15}$ At http://secrettechnology.com/hymns/navigate.html (20 Jan 2010).
} 
the connections between media fragments selected from the database as these fragments fall together in a context that is being constructed in an ongoing manner. Thus, meaning is always involved in a human process of becoming. Such work is accretive in nature and open in terms of ongoing meaning production. (Seaman: 132-133)

Context building, accretion, and openness could be used for describing how meaning is generated by readers' interactions with each of 18 sequences in hymns of the drowning swimmer (2004). Modularity is used at various scales to make the structure of each section or subsection a mirror of the overall structure of the work. There is no set order for choosing between behaviours or attributes associated with each digital element. Readers/players have to decide at random which paths they want to take, and how and when to move the cursor to activate a specific behaviour or to move to a different section/level of the work. As they explore each sequence, they will learn the connection between their own actions and the appearance of linguistic fragments, visual patterns or video animations on the screen. Figuring out how to play/read the work is one important element of its form.

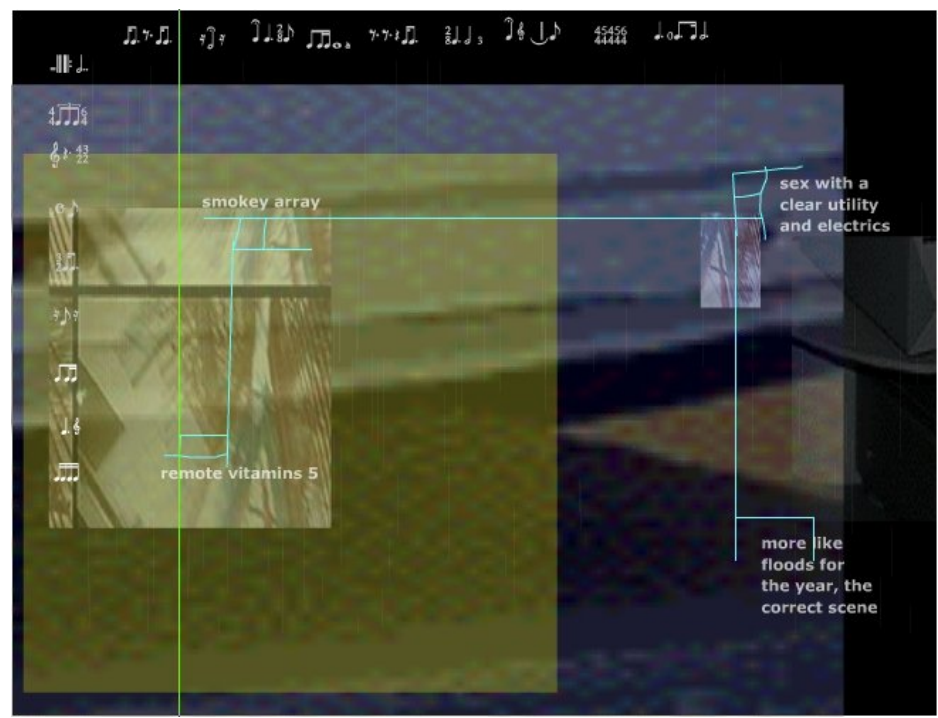

FIGURE 9. Jason Nelson_hymns of the drowning swimmer (2004) 'hymn: eighteen: perhaps we were never entertained' [screen capture]. 


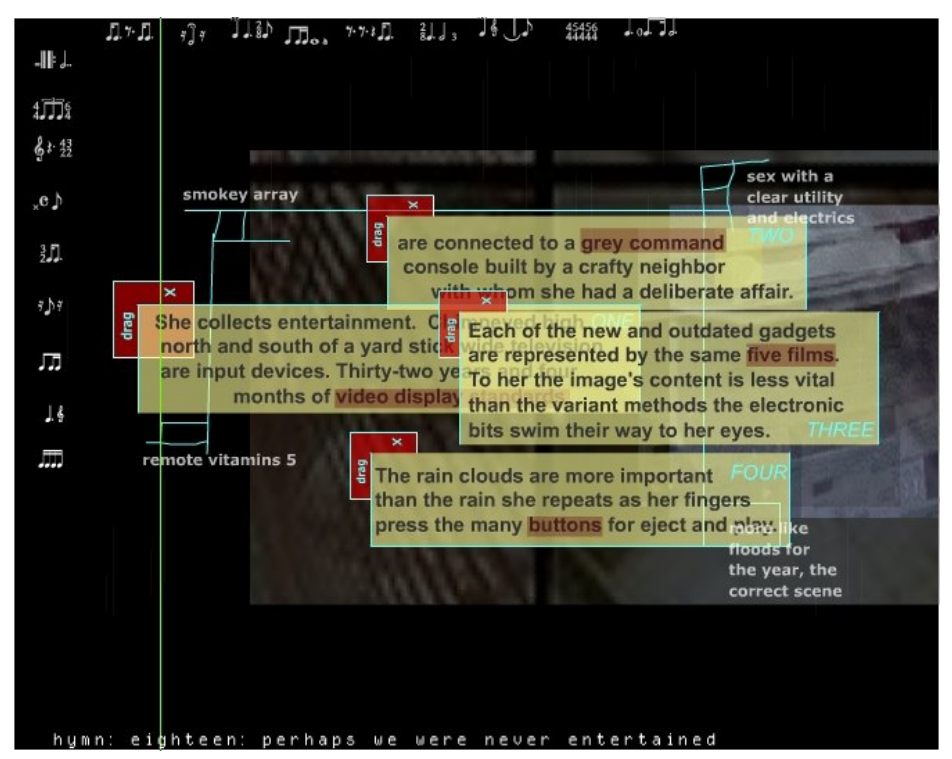

FIGURE 10. Jason Nelson_ hymns of the drowning swimmer (2004)

'hymn: eighteen: perhaps we were never entertained ' [screen capture].

In 'hymn: eighteen: perhaps we were never entertained', for instance, the first screen includes the general menu, moving windows containing video fragments, recursive sound files, and four textual fragments that read (from lower left, clockwise) 'remote vitamins 5', 'smokey array', 'sex with a clear utility and electrics', and 'more like floods for the year, the correct scene' [FIGURE 9]. Each of these four fragments contains an active link that launches a new layer of textual fragments containing longer sentences or sentence fragments, which are presented as rectangular numbered boxes that the reader can drag around the screen, thus composing the four sentence-boxes into a larger textual unit. One of the textual fragments for this second layer reads: 'Each of the new and outdated gadgets are represented by the same five films. To her the image content's less vital than the variant methods the electronic bits swim their way to her eyes.' [FIGURE 10]. Readers then realize that this sentence describes the video fragments looping as moving/opening/closing windows in the background layer. The words 'five films' contain yet another link to a description of the way those video bits were obtained. Similarly highlighted links appear in the remaining sentence boxes, providing further information on those image producing technologies.

As the reader realizes that Jason Nelson's work may be a complex meditation on various media technologies, s/he begins to frame the various elements within this ongoing context. As s/he proceeds, other references will introduce more topics and experiences, such as the various 
references to water and rain. The ensemble of interconnections is never immediately clear or straightforward. In the end meaning arises from the recombination created by this exploratory juxtaposition of elements that become materially associated by virtue of the way signs have been programmed. Multiplicity of media and media convergence depend on digitality as the ultimate abstraction of inscription and reproduction technologies. A system of potential choices will produce unanticipated associations through actual choices. These choices, in turn, will generate new fields of meaning. The work is a machinic assemblage that suggests the shifting nature of meaning through media-element substitutions. At the same time, it seems to emulate the materiality of hypermedia that has come to dominate contemporary electronic writing space. The variety of interfaces, textual content, media-elements, and programming procedures used in hymns of the drowning swimmer (2004) can be seen both as reflection on new media as remediation, and an aesthetic exploration of database culture. Variability as a defining feature of digitality can be appreciated, for instance, in the display screens and algorithmic structure of the following sections: ‘hymn: eight or five: concerning mobility' [FIGURE 11], ‘hymn: seventy and seven: technology from a distance' [FIGURE 12], 'hymn: three hundred and three: aquatic' [FIGURE 13], and 'hymn: one hundred and twenty: rain drawn' [FIGURE 14]) ${ }^{16}$.

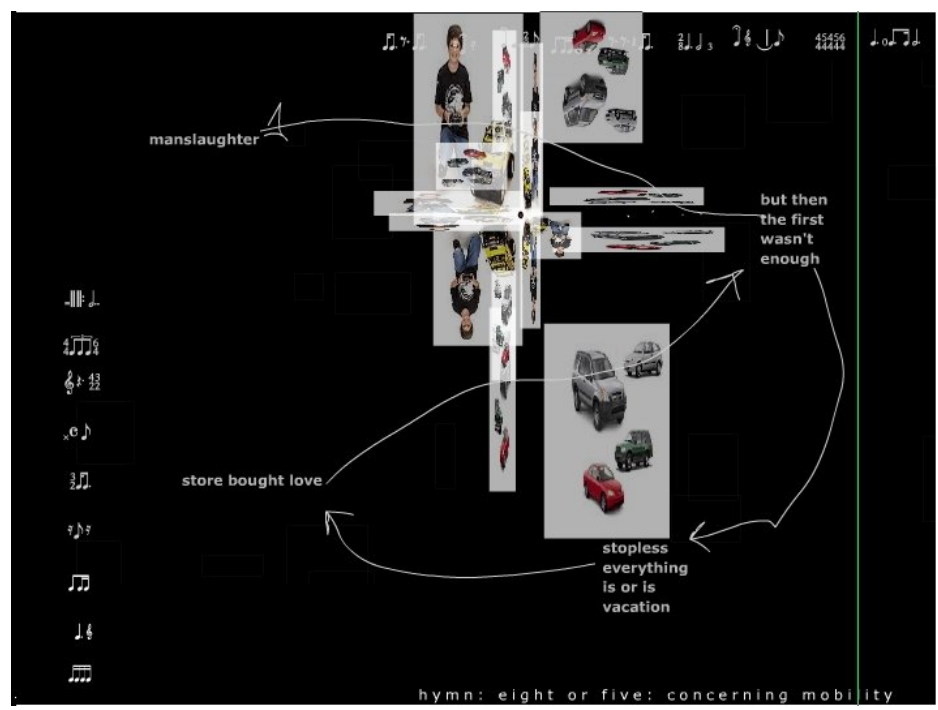

FIGURE 11. Jason Nelson_ hymns of the drowning swimmer (2004)

'hymn: eight or five: concerning mobility' [screen capture].

\footnotetext{
${ }^{16}$ At http://secrettechnology.com/hymns/hymn7.html; http://secrettechnology.com/hymns/hymn12.html; http://secrettechnology.com/hymns/hymn11.html; and http://secrettechnology.com/hymns/hymn8.html (20 Jan 2010).
} 


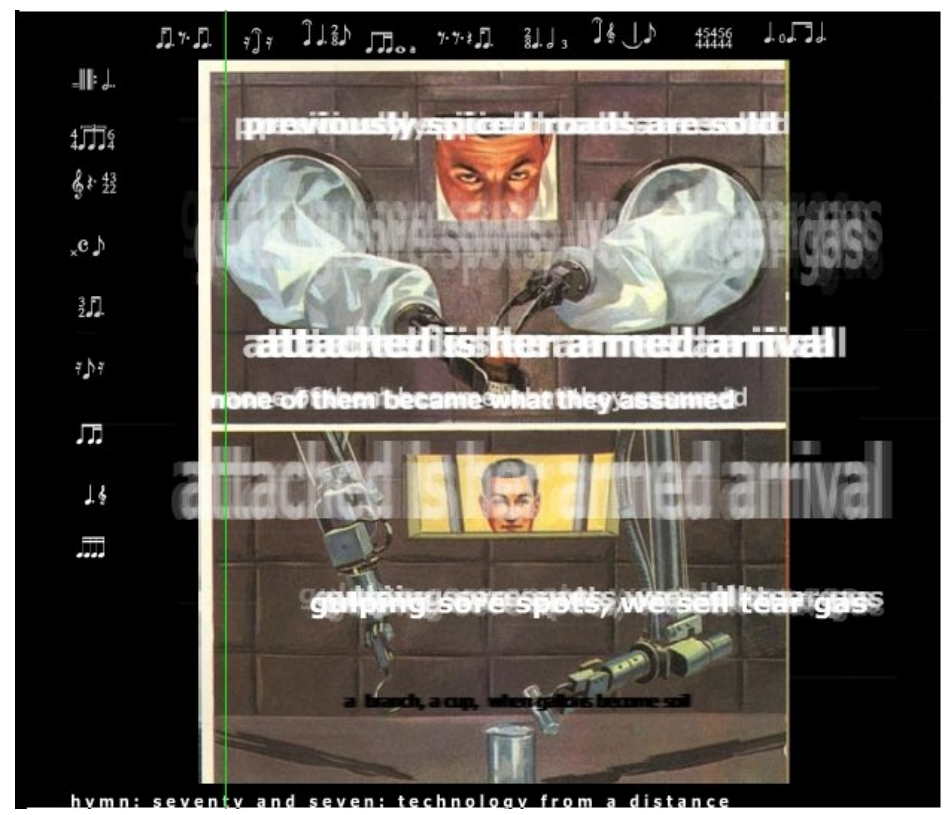

FIGURE 12. Jason Nelson_ hymns of the drowning swimmer (2004) 'hymn: seventy and seven: technology from a distance' [screen capture].

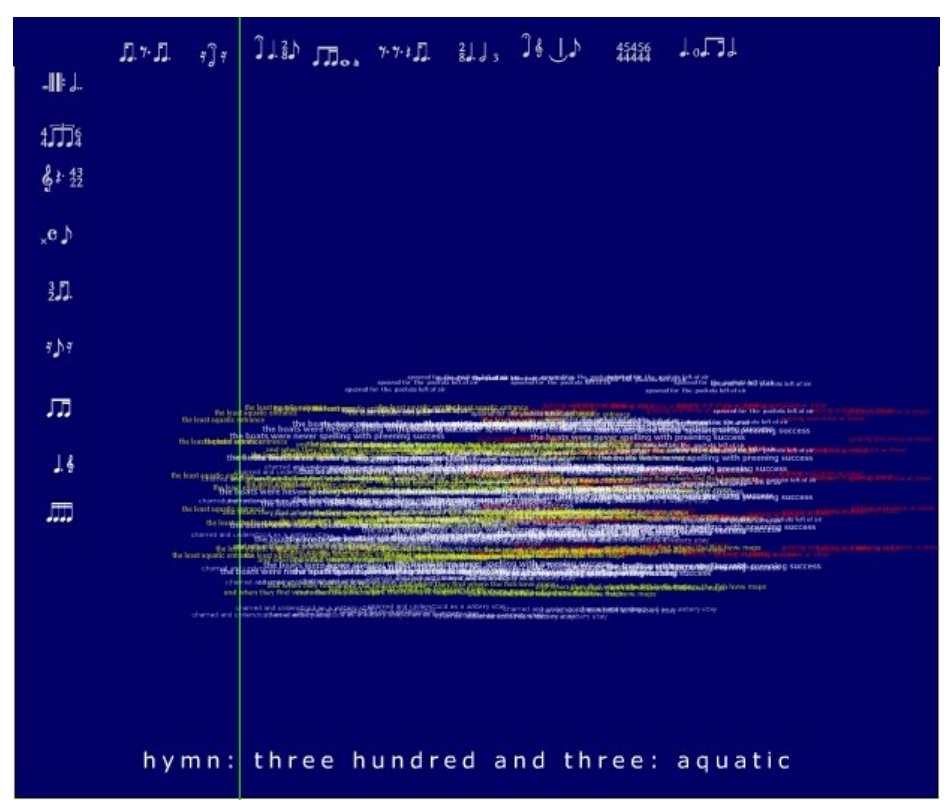

FIGURE 13. Jason Nelson_ hymns of the drowning swimmer (2004)

'hymn: three hundred and three: aquatic' [screen capture]. 


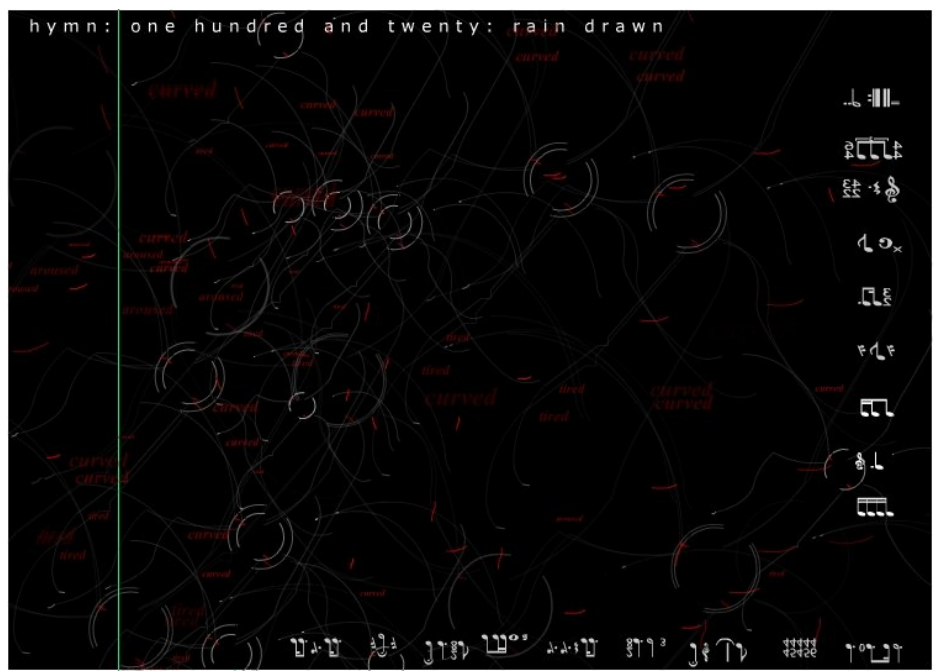

FIGURE 14. Jason Nelson_ hymns of the drowning swimmer (2004)

'hymn: one hundred and twenty: rain drawn' [screen capture].

One of his latest works (with text by Christine Hume) is a virtual three-dimensional literary Rubik's Cube: 'dimension is night is night' (2007). ${ }^{17}$ This is another ergodic work in which the relation between the act of reading and the production of text is given a fractured and disjointed expression. The reader, immersed in the field of signs, has to co-produce his/her textual experience. Textual immersion takes place not at the semantic level of a fictional possible world, but at the material level of the graphic user interface itself. Readers are caught in a field of signifiers that have to be related to each other by virtue of their simultaneous presence, but whose semantic relations are not obvious. Verbal discourse and the electronic objects themselves (sound, image, and text files) are de-familiarized. The $3 \times 3 \times 3$ mechanism of the cube works as a texton, i.e, a generative algorithm that produces a very large number of textual occurrences. ${ }^{18}$ Once activated by the reader in a mouse-mediated haptic interaction, the texton will be displayed as a scripton, i.e., a particular textual sequence. ${ }^{19}$ dimension is night is night (2007) is a playable work, as is made clear by the user interface, which instructs the reader 'how to play/read/recreate'

\section{[FIGURE 15 and FIGURE 16].}

\footnotetext{
${ }^{17}$ At http://www.secrettechnology.com/night/xtine.html (20 Jan 2010). See appendix (below, pp. 35-41) for a diagrammatic analysis of Jason Nelson's segmentation of Christine Hume's text.

${ }^{18}$ Rubik's Cube, a three-dimensional mechanical puzzle, was invented in 1974 by Ernő Rubik. Each of the six faces is covered by 9 stickers, traditionally in the colours white, red, blue, orange, green, and yellow. Nelson has used black, red, blue, green, and yellow for Christine Hume's textual fragments. Virtual rotations emulate the pivot mechanism of the original Rubik's Cube. This mechanism enables each face to turn independently, thus mixing up the texts by twisting an outer third of the Cube $90^{\circ}, 180^{\circ}$ or $270^{\circ}$. There are exactly $43,252,003,274,489,856,000$ permutations, or $8 ! \times 3^{7} \times 12 ! \times 2^{10} \approx 4.33 \times 10^{19}$.

19 'It is useful to distinguish between strings as they appear to readers and strings as they exist in the text, since these may not always be the same. For want of better terms, I call the former scriptons and the latter textons.' (Aarseth 1997: 62).
} 


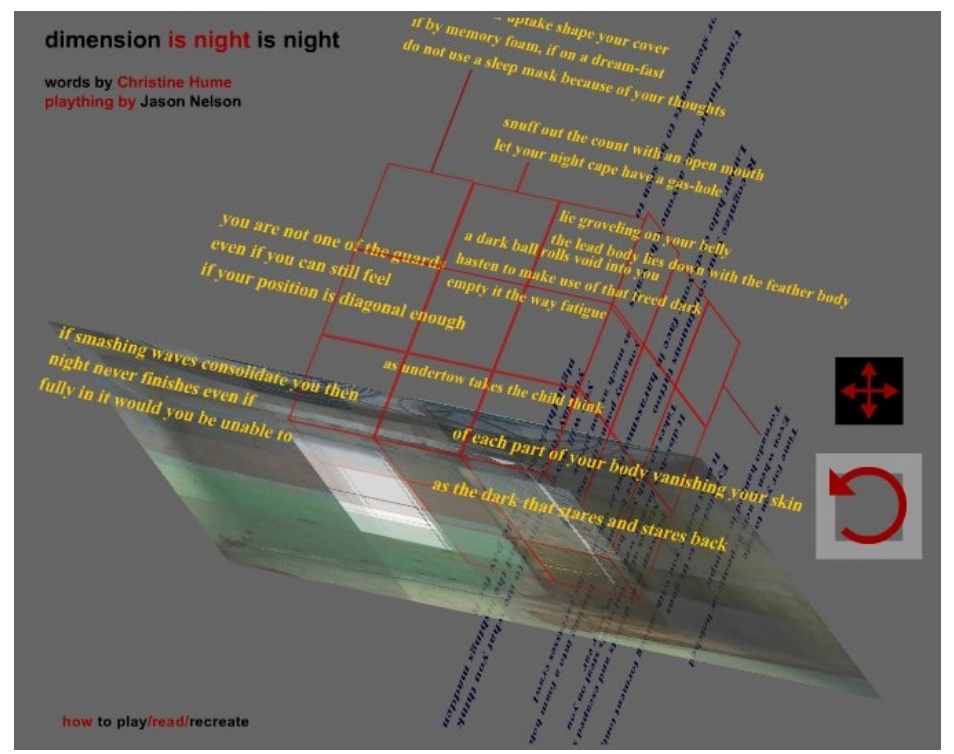

FIGURE 15. Jason Nelson_dimension is night is night (2007) [screen capture].

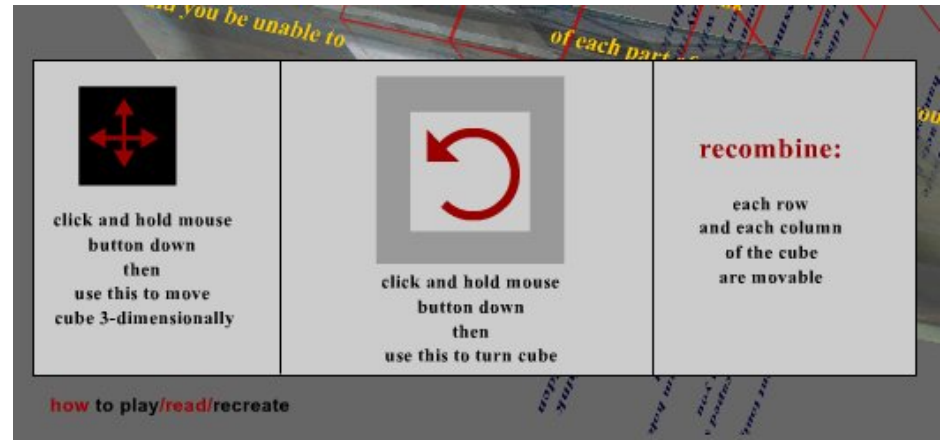

FIGURE 16. Jason Nelson_dimension is night is night (2007): 'how to play/read/recreate' [screen capture].

A particular textual sequence or occurrence recreated by readers' actions never completely loses its fragmentariness, since no totality emerges from the recombination of textual units. The resulting text is always partially illegible because layers with various colours can be simultaneously present, and rotating cube sections will unscramble some lines while scrambling others [FIGURE 17].

Because of the fragmentary, associative, surrealist, and nearly automatic nature of the source text, solving the digital puzzle - i.e. unscrambling the same-coloured lines that make up each cube face - will not make way for a coherent textual experience. Fracture, incompleteness, multiplicity, and 
uncertainty of digital sign fields in Jason Nelson's work foreground reading as always an attempt at reading, never to be fully realized.

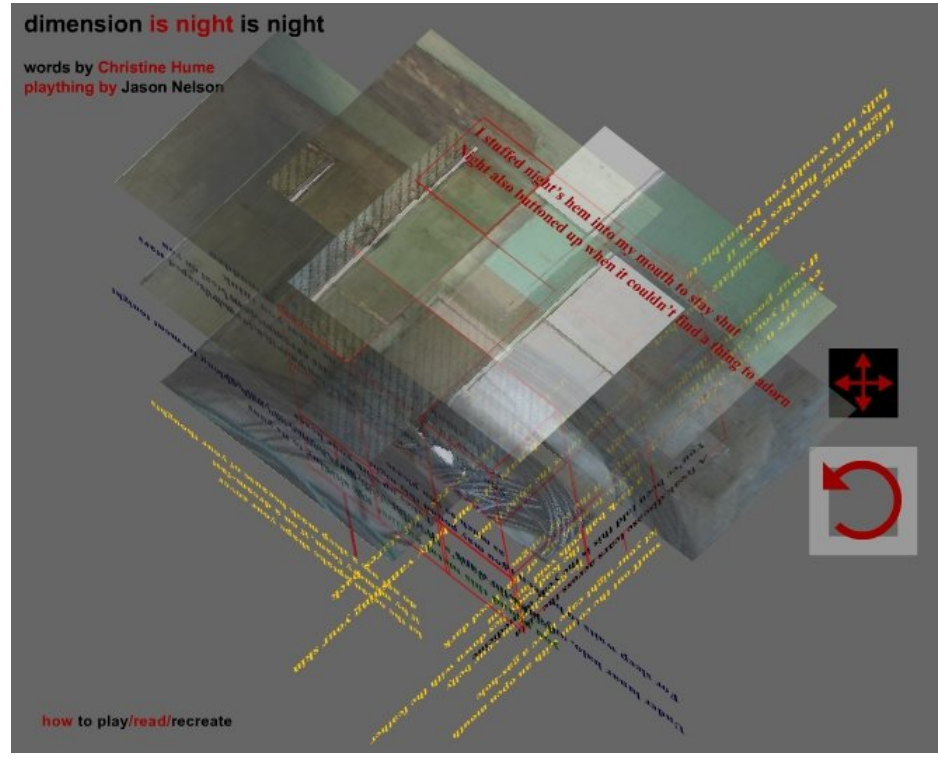

FIGURE 17. Jason Nelson_dimension is night is night (2007) [screen capture].

Jason Nelson's ars combinatoria is based upon Christine Hume's text 'Nocturnal Dimensions of the Future' (see APPENDIX). In its original form, each poetry sequence was followed by a short prose text. Nelson organized his 'plaything' on the basis of 54 units (9 possible positions on each square face $\times 6$ faces). Five cube faces contain lines from Christine Hume's poems, while the sixth face contains one image divided into 9 parts. The image, which could be a filtered colour photograph or a painting, suggests an indoor space with a door opening onto the outside. The indoor space is structured on the basis of darkness/light contrast, incoming light possibly coming from the sky as reflected by the sea. Nelson broke up Hume's four poems into five groups of lines. The five groups follow the original line sequence, with only two exceptions: the lines 'your lordish hours form unknown conduits/ and unknown songs empty into my lungs' (II. 16-17, $3^{\text {rd }}$ sequence) were left out. They were replaced by the lines 'is a way of worship if smashing waves / do not listen for where the sound ends' (i.e., II. 14-15, $4^{\text {th }}$ sequence - in Nelson's cube these lines were interpolated in the $3^{\text {rd }}$ sequence). Groups are distinguished by colour (red, black, blue, green, and yellow) and they are composed of 9 units (usually 2 or 3 lines per unit). Each unit is linked to one of the 9 squares on each face. Only the yellow group has 8 units, which means that there is one vacant position on the 
corresponding cell of the nine-square table of the yellow face. [TABLE 1, pp. 44-45, in the appendix identifies each unit and its place in the original text. TABLE 2, p. 46, describes the cube's structure and the distribution pattern for the various textual units].

The automatic and surrealist associations in the original text already contain a relatively high degree of randomness. However, the prose texts that follow each poem sequence establish a referential and, at times, an autobiographical context for its contorted symbolic and metaphoric displacements. The continuing presence of the pronoun ' l', in particular, give those prose fragments a textual coherence that is absent from the verse sections. The print text seems to live from this tension between determined and undetermined referential meaning. Several lines can be read as relatively autonomous syntactic units or as part of larger discursive units formed by groups of lines. Repeated metaphorical displacements result in a dense symbolic texture.

Jason Nelson has increased the semantic and syntactic autonomy of the source text's fragments by further breaking up each text into groups of one, two, or three lines, and by programming permutations according to the cube's multiple rotational axes. When played by readers, his cubic textual machine generates thousands of random combinations, in which line groups change position, superimpose, and mix. Rotating the virtual cube along its axes will sometimes expand and sometimes contract textual interlineations and textual transparency, resulting in different degrees of legibility [FIGURE 18]. Sentences, words, and letters are often only partially legible. This layering of textual position, transparency and opacity, as well as the combination of image and character textuality emulate the graphic environment of digital space itself. Readers experience digital text as an assemblage of palimpsest fragments, where sense emerges from changing and transient patterns, which are generated by the player/reader's interaction with the digital object itself. Nelson's algorithmic organization of the square units works by exponentiating the principle of juxtaposition and association, already present in the original text. Readers/players experience the semantic and syntactic gap that prevents immediate textual cohesion and textual coherence. This turbulent associative and permutative mechanism reveals the programmability of signs as a poetical tool for choreographing the reading of cybertexts. The gaming element of this choreography is also the work's main self-reflective device. 

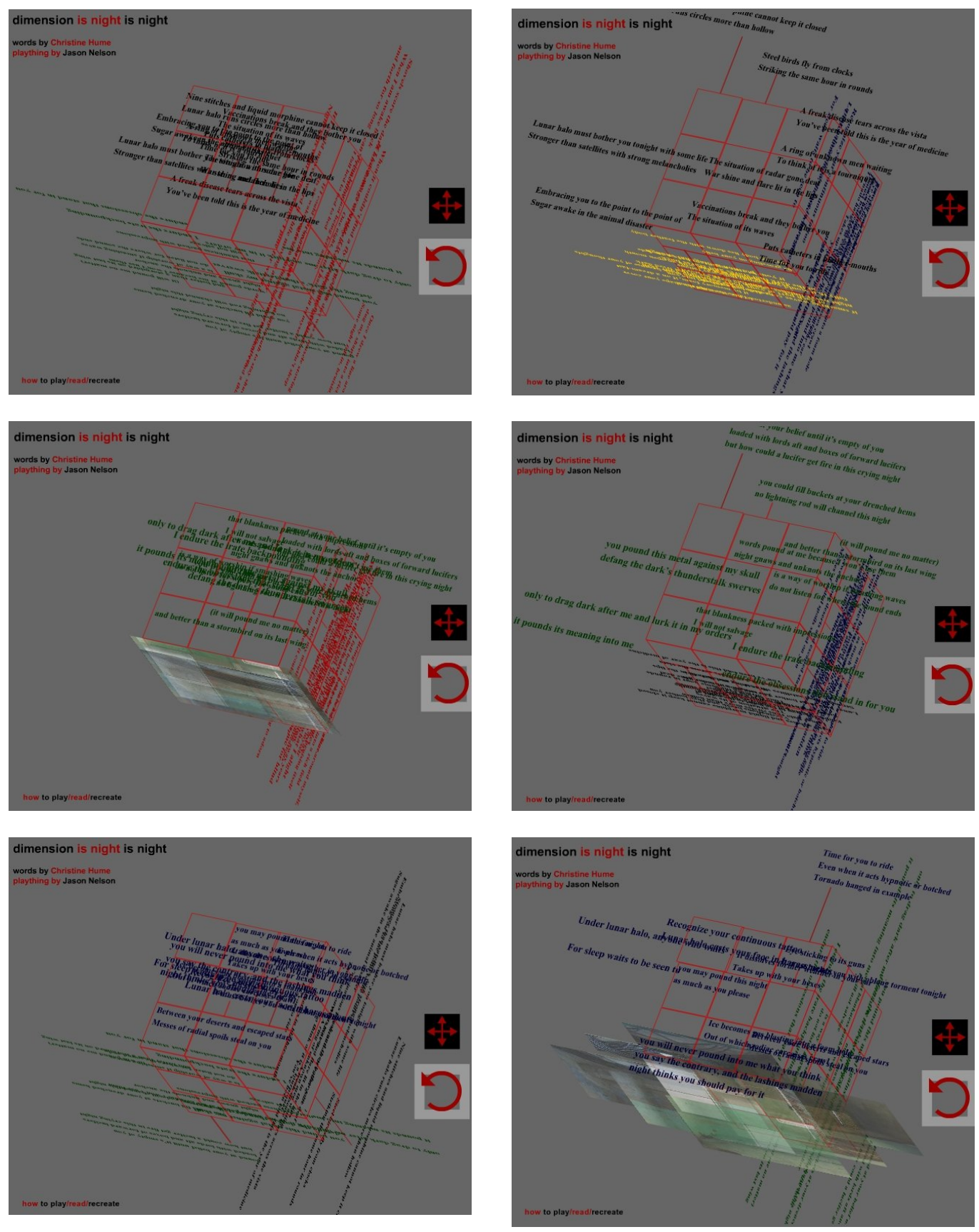

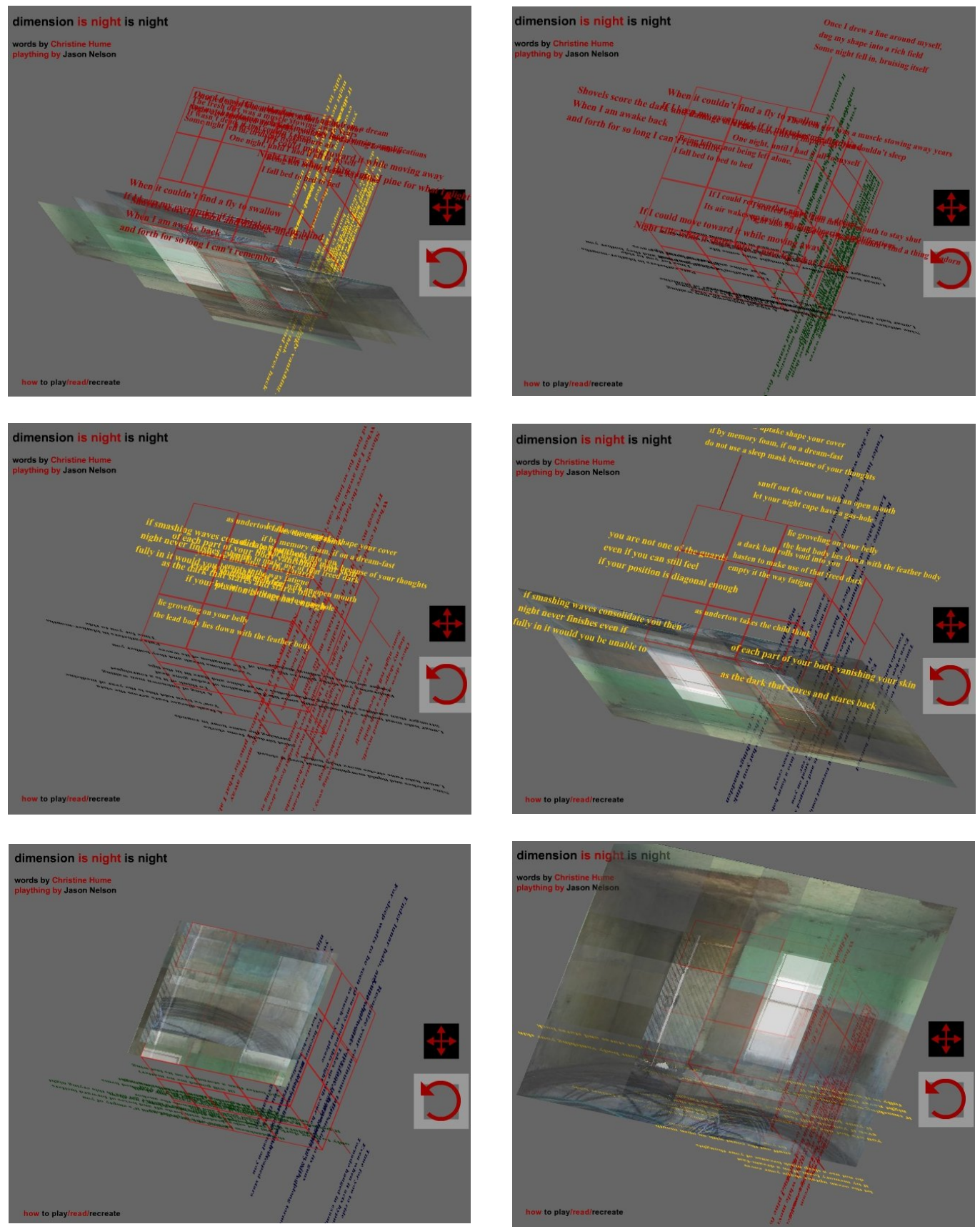

FIGURE 18. Jason Nelson_dimension is night is night (2007): 12 textual configurations of one-colour cube faces in contracted and expanded forms [screen capture]. 
Embedded in the algorithmic culture of the digital age, Jason Nelson's electronic poem redefines the role of the reader as a player. In his programmable works readers become aware of the role of software code as a specific textual layer that instructs the hardware of the machine to perform operations on data. As in computer video games, the reader/player experiences the codependence between machine actions and operator actions, i.e., the fact that they are part of the same algorithmic system. ${ }^{20}$ The syntactic and semantic structure of natural language is further constrained by the codified rules operating the machine. Three-dimensional permutations of column and row imply that this work's formal materiality can be instantiated in many textual combinations. Writing and reading are shown as actions in the cybernetic software system that produces the algorithmic poem. Reading has been scripted as a series of actions that are required to execute parts of the code. Through his/her gaming action, the reader/player explores new possibilities for natural and computer language opened up by algorithmic machines: the programmability of language and signs; the recovery of time for literary art; the discovery of complex surfaces for writing; the transience of forms and meaning; the randomness and indeterminacy of signifiers; the configurative display of signs; the presence of the reading act; etc.

Self-reflexivity in codex and computer works contains useful critical insights about the materiality of both media. Johanna Drucker and Jason Nelson's aesthetic experiments with the materialities of bibliographic and digital codes provide new modes of critical inquiry into the function of material differences in the creation of form and in the production meaning. A general theory of self-reflexive formal operations in books and computers will provide a more powerful description of writing and reading acts. In the present context of rapidly evolving transliteracy technologies, this understanding of self-reflexivity may contribute to a better understanding of the nature of bibliographic and electronic writing and reading acts - in themselves and in their relationships - as both material and social events.

\footnotetext{
${ }^{20}$ I borrow from Alexander R. Galloway's definition of the video game as an action-based medium: '[...]an active medium is one whose very materiality moves and restructures itself - pixels turning on and off, bits shifting in hardware registers, disks spinning up and spinning down.' (2006: 3).
} 
APPENDIX

'Nocturnal Dimensions of the Future' and 'dimension is night is night': Jason Nelson's Multimodal Recoding of Christine Hume's Poem ${ }^{21}$

Nocturnal Dimensions of the Future ${ }^{22}$

Once I drew a line around myself, dug my shape into a rich field

Some night fell in, bruising itself

The fresh dirt was a muscle stowing away years

It wasn't dead, it just couldn't sleep

I stuffed night's hem into my mouth to stay shut

Night also buttoned up when it couldn't find a thing to adorn

When it couldn't find a fly to swallow

If I keep my eyes quiet, if it mistakes me for blind

I dry heave fits of impure air

One night, until I had it all to myself

If I could retrieve that night from a dream

Its air wakes up inside my lung, bearing amplifications

Shovels score the dark and damage allergies

When I am awake back and forth for so long I can't remember

Being left or not being left alone, I fall bed to bed to bed

If I could move toward it while moving away

Night kills what it shifts into; I pine for what I alight

\footnotetext{
${ }^{21}$ This appendix contains Christine Hume's sequence of poems 'Nocturnal Dimensions of the Future', which provided the text for Jason Nelson's ars combinatoria.

22 Cf. The Other Voices International Project, Volume 23 (2005),

http://www.othervoicespoetry.org/vol23/hume/nocturnal.htm (20 Feb 2010). The fragment beginning 'Nine stitches and liquid morphine cannot keep it closed' appeared, in a slightly different version, under the title 'Lunar Halo' in Typo Magazine, Issue 6 (2005) http://www.typomag.com/issue06/hume.html (20 Feb 2010).
} 
I looked in all eight directions then spread my tiger's skin on the floor. Before the public mind kicked in, I surveyed an inner shore. Its crystal facets operated on me. I lost my lights and began my midnight thus: mental feet, mental lake, little mental pines, mental mile around the muzzle. I aimed my automatic at that outlandish organ hanging in the sky like a dazed stone. Its sea expression wet the evening air; I captained the tempest there. Looking too long into the distant human pupil, I sharpened my harpoon. But my hands could not be organized. I wanted to tightrope up there on a mental binge. I reached for my quiver, and soon arrows ascended the degrees, bristling. My bird described a failure one depth below time. The moment rotated. Its color was extreme. In a heavy steel helmet, I matched that orb and tried to tackle it by a hundred mental muscles. The more I bruised it, the more I couldn't see it. If I could turn it open like a glass knob, feel my way in. If I could tongue out its creamy mouth. If I could tickle it and bounce it on my knee. If I could dress it up. If it would fist me, if I could force it. The more I battered that moon, the more I could be it.

Nine stitches and liquid morphine cannot keep it closed

Lunar halo runs circles more than hollow

Steel birds fly from clocks

Striking the same hour in rounds

A freak disease tears across the vista

You've been told this is the year of medicine

Lunar halo must bother you tonight with some life

Stronger than satellites with strong melancholies

The situation of radar gone deaf

War shine and flare lit in the lips

A ring of unknown men waiting

To think of it is a tourniquet

Embracing you to the point to the point of

Sugar awake in the animal disaster

Vaccinations break and they bother you 
The situation of its waves

Puts catheters in blather-mouths

Time for you to ride

Even when it acts hypnotic or botched

Tornado hanged in example

Eye sticking to its guns

It must bother you with oblong torment tonight

Between your deserts and escaped stars

Messes of radial spoils steal on you

Recognize your continuous tattoo

Lunar halo casts your face in harassments

It dissolves former weather in your ear

Takes up with your hexes

Ice becomes gas blasting into a foam hole

Out of which zodiac carcasses crawl

Under lunar halo, anyone who waits

For sleep waits to be seen to

My first mind is night driving on and on. My blood evolved from this pitch and one night's tar accumulated in my mouth. If I go with my face made up, occult currents get plumbed. Their magnetic air is self-taught and not handled well. If I am fully in night, I cannot think ahead or use a song to get there. Night makes time by not remembering to go back. I make it mine by owning up to what I am not. Stars are swinging doors that miracle away the shift. I am driving high into the taste of vanishing and starting points. Their arrows double-joint the dark. I am driving into my own eyes. Yellow lights pill the horizon hills. If I keep night to my right side, it ramifies at me until my solitudes splinter. My pulse stuck to the signal: turnoverturnoverturn. 
you may pound this night as much as you please

you will never pound into me what you think

you say the contrary, and the lashings madden

night thinks you should pay for it

pound at your belief until it's empty of you

loaded with lords aft and boxes of forward lucifers

but how could a lucifer get fire in this crying night

you could fill buckets at your drenched hems

no lightning rod will channel this night

(it will pound me no matter)

and better than a stormbird on its last wing

you pound this metal against my skull

defang the dark's thunderstalk swerves

words pound at me because I won't use them

night gnaws and unknots the anchor

your lordish hours form unknown conduits

and unknown songs empty into my lungs

only to drag dark after me and lurk it in my orders

it pounds its meaning into me

that blankness packed with impressions I will not salvage

I endure the irate backpounding

endure the obsessions that stand in for you

I borrowed hours to finish you and borrowed a dream to falsify my night. I borrowed night after night until I had one to myself-abandoned that night. I borrowed a prayer in owl light, borrowed devotion and the words. To be sure, I borrowed a cocktail dress. Felt my way along night-blooming creepers until I felt extravagant with a cigarette. I borrowed that and your infant phantom. I took it on credit. I took out what I took me to be. I borrowed a stone room to keep you and kept you in the dark. I grew another dark and owned its circulation. Borrowed a second wind, and left a note on fair trade. I 
made the words fall, made the falls faster. Into a hole I dug. I tried to rescue that silence. I entered it in my lab coat, and I entered it on a black horse. Driven to the wrong address, I burrowed in. I borrowed your only idea and gave away darkness. I tried to give way, to the dark I tried to give a way.

let the ocean uptake shape your cover if by memory foam, if on a dream-fast do not use a sleep mask because of your thoughts snuff out the count with an open mouth let your night cape have a gas-hole lie groveling on your belly the lead body lies down with the feather body you are not one of the guards even if you can still feel if your position is diagonal enough a dark ball rolls void into you hasten to make use of that freed dark empty it the way fatigue is a way of worship if smashing waves do not listen for where the sound ends if smashing waves consolidate you then night never finishes even if fully in it would you be unable to as undertow takes the child think of each part of your body vanishing your skin as the dark that stares and stares back 


\begin{tabular}{|c|c|c|c|}
\hline \multicolumn{2}{|c|}{$\begin{array}{l}\text { 'Nocturnal } \\
\text { Dimensions of the } \\
\text { Future' }\end{array}$} & \multicolumn{2}{|r|}{ 'dimension is night is night' } \\
\hline sequence & lines & squares & text colours on the square faces \\
\hline \multirow{10}{*}{$1 \mathrm{st}$} & [1-2] & Red 1 & $\begin{array}{l}\text { Once I drew a line around myself } \\
\text { dug my shape into a rich field } \\
\text { Some night fell in, bruising itself }\end{array}$ \\
\hline & [3-4] & Red 2 & $\begin{array}{l}\text { The fresh dirt was a muscle stowing away years } \\
\text { It wasn't dead, it just couldn't sleep }\end{array}$ \\
\hline & {$[5-6]$} & Red 3 & $\begin{array}{l}\text { I stuffed night's hem into my mouth to stay shut } \\
\text { Night also buttoned up when it couldn't find a thing to adorn }\end{array}$ \\
\hline & [7-8] & Red 4 & $\begin{array}{l}\text { When it couldn't find a fly to swallow } \\
\text { If I keep my eyes quiet, if it mistakes me for the blind }\end{array}$ \\
\hline & [9-10] & Red 5 & $\begin{array}{l}\text { I dry heave fits of impure air } \\
\text { One night, until I had it all to myself }\end{array}$ \\
\hline & {$[11-12]$} & Red 6 & $\begin{array}{l}\text { If I could retrieve that night from a dream } \\
\text { Its air wakes up inside my lung, bearing amplifications }\end{array}$ \\
\hline & {$[13-14]$} & Red 7 & $\begin{array}{l}\text { Shovels score the dark and damage allergies } \\
\text { When I am awake back } \\
\text { and forth for so long I can't remember }\end{array}$ \\
\hline & [15] & Red 8 & $\begin{array}{l}\text { Being left or not being left alone, } \\
\text { I fall bed to bed to bed }\end{array}$ \\
\hline & [16-17] & Red 9 & $\begin{array}{l}\text { If I could move toward it while moving away } \\
\text { Night kills what it shifts into; I pine for what I alight }\end{array}$ \\
\hline & 17 lines & 9 squares & \\
\hline \multirow{16}{*}{ 2nd } & [1-2] & Black 1 & $\begin{array}{l}\text { Nine stiches and liquid morphine cannot keep it closed } \\
\text { Lunar halo runs circles more than hollow }\end{array}$ \\
\hline & [3-4] & Black 2 & $\begin{array}{l}\text { Still birds fly from clocks } \\
\text { Striking the same hour in rounds }\end{array}$ \\
\hline & [5-6] & Black 3 & $\begin{array}{l}\text { A freak disease tears across the vista } \\
\text { You've been told this is the year of medicine }\end{array}$ \\
\hline & [7-8] & Black 4 & $\begin{array}{l}\text { Lunar halo must bother you tonight with some life } \\
\text { Stronger than satellites with strong melancholies }\end{array}$ \\
\hline & [9-10] & Black 5 & $\begin{array}{l}\text { The situation of radar gone deaf } \\
\text { War shine and flare lit in the lips }\end{array}$ \\
\hline & {$[11-12]$} & Black 6 & $\begin{array}{l}\text { A ring of unknown men waiting } \\
\text { To think of it is a tourniquet }\end{array}$ \\
\hline & {$[13-14]$} & Black 7 & $\begin{array}{l}\text { Embracing you to the point to the point of } \\
\text { Sugar awake in the animal disaster [ }\end{array}$ \\
\hline & {$[15-16]$} & Black 8 & $\begin{array}{l}\text { Vaccinations break and they bother you } \\
\text { The situation of its waves }\end{array}$ \\
\hline & [17-18] & Black 9 & $\begin{array}{l}\text { Puts catheters in blathers-mouth } \\
\text { Time for you to ride }\end{array}$ \\
\hline & [19-20] & Blue 1 & $\begin{array}{l}\text { Time for you to ride } \\
\text { Even when it acts hypnotic or botched } \\
\text { Tornado hanged in example }\end{array}$ \\
\hline & [20-21] & Blue 2 & $\begin{array}{l}\text { Eye sticking to its guns } \\
\text { It must bother you with oblong torment tonight }\end{array}$ \\
\hline & [23-24] & Blue 3 & $\begin{array}{l}\text { Between you deserts and escaped stars } \\
\text { Masses of radial spoils steal on you }\end{array}$ \\
\hline & [25-26] & Blue 4 & $\begin{array}{l}\text { Recognize your continuous tattoo } \\
\text { Lunar halo casts your face in harassments }\end{array}$ \\
\hline & [27-28] & Blue 5 & $\begin{array}{l}\text { It dissolves former weather in your ear } \\
\text { Takes up with your hexes }\end{array}$ \\
\hline & [29-30] & Blue 6 & $\begin{array}{l}\text { Ice becomes gas blasting into a foam hole } \\
\text { Out of which zodiac carcasses crawl }\end{array}$ \\
\hline & [31-32] & Blue 7 & $\begin{array}{l}\text { Under lunar halo, anyone who waits } \\
\text { For sleep waits to be seen to }\end{array}$ \\
\hline & 32 lines & $\begin{array}{c}16 \\
\text { squares }\end{array}$ & \\
\hline
\end{tabular}




\begin{tabular}{|c|c|c|c|}
\hline \multicolumn{2}{|c|}{$\begin{array}{l}\text { 'Nocturnal } \\
\text { Dimensions of the } \\
\text { Future' }\end{array}$} & \multicolumn{2}{|r|}{ 'dimension is night is night' } \\
\hline sequence & lines & squares & text colours on the square faces \\
\hline \multirow{11}{*}{ 3rd } & {$[1]$} & Blue 8 & $\begin{array}{l}\text { you may pound this night } \\
\text { as much as you please }\end{array}$ \\
\hline & [2-4] & Blue 9 & $\begin{array}{l}\text { you will never pound into me what you think } \\
\text { you say the contrary and the lashings madden } \\
\text { night thinks you should pay for it }\end{array}$ \\
\hline & [5-7] & Green 1 & $\begin{array}{l}\text { pound at your belief until it's empty of you } \\
\text { loaded with lords aft and boxes of forward lucifers } \\
\text { but how could a lucifer get fire in this crying night }\end{array}$ \\
\hline & [8-9] & Green 2 & $\begin{array}{l}\text { you could fill buckets with your drenched hems } \\
\text { no lightning rod will channel this night }\end{array}$ \\
\hline & {$[10-11]$} & Green 3 & $\begin{array}{l}\text { (it will pound me no matter) } \\
\text { and better than a stormbird on its last wing }\end{array}$ \\
\hline & [12-13] & Green 4 & $\begin{array}{l}\text { you pound this metal against my skull } \\
\text { defang the dark's thunderstalk swerves }\end{array}$ \\
\hline & {$[14-15]$} & Green 5 & $\begin{array}{l}\text { words pound at me because I won't use them } \\
\text { night gnaws and unknots the anchor }\end{array}$ \\
\hline & {$[16-17]$} & -------- & $\begin{array}{l}\text { your lordish hours form unknown conduits } \\
\text { and unknown songs empty into my lungs [excluded lines] }\end{array}$ \\
\hline & {$[18-19]$} & Green 7 & $\begin{array}{l}\text { only to drag dark after me and lurk it in my orders } \\
\text { it pound its meaning into me }\end{array}$ \\
\hline & [20] & Green 8 & $\begin{array}{l}\text { that blankness packed with impressions } \\
\text { I will not salvage }\end{array}$ \\
\hline & {$[21-22]$} & Green 9 & $\begin{array}{l}\text { I endure the irate backpounding } \\
\text { endure the obsessions that stand in for you }\end{array}$ \\
\hline & 22 lines & $\begin{array}{c}10 \\
\text { squares }\end{array}$ & \\
\hline \multirow{10}{*}{ 4th } & [1-3] & Yellow 1 & $\begin{array}{l}\text { let the ocean uptake shape your cover } \\
\text { if by memory foam, if on a dream-fast } \\
\text { do not use a sleep mask because of your thoughts }\end{array}$ \\
\hline & [4-5] & Yellow 2 & $\begin{array}{l}\text { snuff out the count with an open mouth } \\
\text { let your night cape have a gas-hole }\end{array}$ \\
\hline & [6-7] & Yellow 3 & $\begin{array}{l}\text { Y3 [6-7] lie grovelling in your belly } \\
\text { the lead body lies down with the feather body }\end{array}$ \\
\hline & {$[8-10]$} & Yellow 4 & $\begin{array}{l}\text { you are not one of the guards } \\
\text { even if you can still feel } \\
\text { if your position is diagonal enough }\end{array}$ \\
\hline & {$[11-13]$} & Yellow 5 & $\begin{array}{l}\text { a dark ball rolls void into you } \\
\text { hasten to make use of that freed dark } \\
\text { empty it the way fatigue }\end{array}$ \\
\hline & {$[14-15]$} & Green 6 & $\begin{array}{l}\text { is a way of worship if smashing waves } \\
\text { do not listen for where the sound ends }\end{array}$ \\
\hline & [16-18] & Yellow 6 & $\begin{array}{l}\text { if smashing waves consolidate you then } \\
\text { night never finishes even if } \\
\text { fully in it would you be unable to }\end{array}$ \\
\hline & [19] & Yellow 7 & as undertow takes the child think \\
\hline & {$[20-21]$} & Yellow 8 & $\begin{array}{l}\text { of each part of your body vanishing skin } \\
\text { as the dark stares and stares back }\end{array}$ \\
\hline & 21 lines & 9 squares & \\
\hline
\end{tabular}

TABLE 1. Segmentation of Christine Hume's 'Nocturnal Dimensions of the Future' in Jason Nelson's 'dimension is night is night'. 


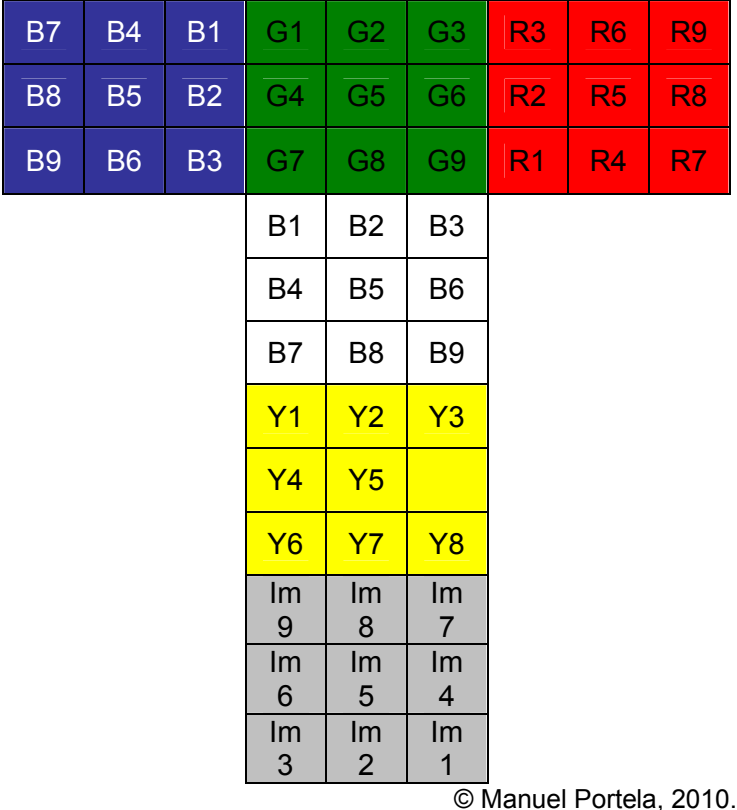

TABLE 2. 54 Textual (juxta)positions: diagram for the cube in Jason Nelson's 'dimension is night is night' (2007). 
A. Works Cited

Aarseth, Espen (1997). Cybertext. Perspectives on Ergodic Literature. Baltimore: Johns Hopkins University Press.

Bolter, Jay David (2001). Writing Space: Computers, Hypertext, and the Remediation of Print, Mahwah, New Jersey, Lawrence ErlBaum Associates Publishers [new revised edition; 1st ed. 1991]

Bolter, Jay David \& Richard Grusin (2000). Remediation: Understanding New Media, Cambridge, Massachusetts, MIT Press [ $1^{\text {a }}$ ed. 1999].

Bootz, Phillippe (2006). 'Digital Poetry: From Cybertext to Programmed Forms', Leonardo Electronic Almanac, Special Issue: New Media and Poetics, ed. Tim Peterson, Vol. 14.5-6 (Sept 2006) http://leoalmanac.org/journal/Vol 14/lea v14 n05-06/pbootz.asp (20 Feb 2010). Cayley, John (2006). 'Time Code Language: New Media Poetics and Programmed Signification', in Digital Media Revisited: Theoretical and Conceptual Innovation in Digital Domains, eds. Gunnar Liestol, Andrew Morrison \& Terje Rasmussen. Cambridge, Mass: MIT Press, 307334.

Drucker, Johanna (1994). A Chronology of Books from 1970 to 1994, written on occasion of the show at Granary Books, New York City, June 1994, http://epc.buffalo.edu/authors/drucker/chron.html (20 Feb 2010).

Drucker, Johanna (1995). The Century of Artists' Books, New York: Granary Books, 1995.

Drucker, Johanna (1997). 'The Self-Conscious Codex: Artists' Books and Electronic Media', in SubStance, Vol. 26, No. 1, Issue 82 (Special Issue: Metamorphoses of the Book): 93-112.

Drucker, Johanna (1999). 'Experimental Narrative and Artists' Books', in Journal of Artists' Books, Fall 1999, Issue 12, pp. 3-25 http://www.journalofartistsbooks.org/past/pdfs//JAB12.pdf (20 Feb 2010).

Drucker, Johanna (2007). 'Performative Metatexts in Metadata, and Mark-up', European Journal of English Studies, 11.2, 177-191.

Drucker, Johanna (2008). 'The Virtual Codex from Page Space to E-space', in A Companion to Digital Literary Studies, Susan Schreibman and Ray Siemens, eds.Oxford: Blackwell. http://www.digitalhumanities.org/companion/view?docld=blackwell/9781405148641/9781405 148641. $x \mathrm{ml}$ \&chunk.id=ss1-5-5\&toc. depth=1\&toc.id=ss1-5-5\&brand=9781405148641 brand http://www.philobiblon.com/drucker/ (20 Feb 2010).

Drucker, Johanna (2009). SpecLab: Digital Aesthetics and Projects in Speculative Computing, Chicago: Chicago University Press.

Drucker, Johanna (1977). From A to Z: Our An (Collective Specifics) an impartial bibliography, Incidents in a Non-Relationship or: how I came to not know who is, Oakland/Berkeley, CA: Chased Press, in http://www.artistsbooksonline.org/works/atoz.xml (19 Jan 2010).

Drucker, Johanna (1978). Experience of the Medium, Amsterdam: Johanna Drucker. http://www.artistsbooksonline.org/works/expm.xml (19 Jan 2010). 
Drucker, Johanna (1988). Bookscape, Dallas, Texas: Abacus, Potes and Poets Press Inc. http://www.artistsbooksonline.org/works/bksc.xml (19 Jan 2010).

Drucker, Johanna (1989). The Word Made Flesh. New York: Druckwerk [New York: Granary Books, $2^{\text {nd }}$ ed., 1996] http://www.artistsbooksonline.org/works/wmfl.xml (19 Jan 2010).

Drucker, Johanna (1990). The History of the/my Wor(I)d, New York: Druckwerk [New York: Granary Books, $2^{\text {nd }}$ ed., 1995] http://www.artistsbooksonline.org/works/hist.xml (19 Jan 2010).

Drucker, Johanna (1994). Narratology. New York: Johanna Drucker. http://www.artistsbooksonline.org/works/narr.xml (19 Jan 2010).

Funkhouser, Chris (2007). Prehistoric Digital Poetry: An Archaeology of Forms, 1959-1995. Tuscaloosa, AL: University of Alabama Press.

Galloway, Alexander R. (2006). Gaming: Essays on Algorithmic Culture. Minneapolis: University of Minnesota Press.

Glazier, Loss Pequeño (2002). Digital Poetics: The Making of E-Poetries. Tuscaloosa, AL: University of Alabama Press.

Glazier, Loss Pequeño (2006). 'Code as Language', in Leonardo Electronic Almanac, Special Issue: New Media and Poetics, ed. Tim Peterson, Vol. 14.5-6 (Sept 2006) http://leoalmanac.org/journal/Vol 14/lea v14 n05-06/lglazier.asp (20 Feb 2010)

Hayles, N. Katherine (2002). Writing Machines. Cambridge, Mass: MIT Press.

Hayles, N. Katherine (2006). 'The Time of Digital Poetry: From Object to Event', in New Media Poetics: Contexts, Technotexts, and Theories, ed. Adalaide Morris and Thomas Swiss, Cambridge, Mass: MIT Press, 143-164.

Hayles, N. Katherine (2008). Electronic Literature: New Horizons for the Literary. Notre Dame, Indiana: University of Notre Dame.

Howard, Nicole (2009). The Book: The Life Story of a Technology. Baltimore: The Johns Hopkins University Press [Greenwood Press, 2006].

Johns, Adrian. The Nature of the Book: Print and Knowledge in the Making, Chicago: University of Chicago Press, 1998.

Kirschenbaum, Matthew G. (2008). Mechanisms: New Media and the Forensic Imagination. Cambridge, Mass: MIT Press.

Landow, George P. (2006). Hypertext 3.0: Critical Theory and New Media in an Era of Globalizatio. Baltimore, Johns Hopkins University Press [revised edition; 1992, 1997].

Manovich, Lev (2001). The Language of New Media. Cambridge, MA: MIT Press.

Manovich, Lev (2007). 'Database as Symbolic Form', in Database Aesthetics: Art in the Age of Information Overflow, edited by Victoria Vesna, Minneapolis: University of Minnesota Press, pp. 39-60.

Manovich, Lev (2008). Software Takes Command. Published online at http://lab.softwarestudies.com/2008/11/softbook.html (20 Feb 2010)

McCaffery, Steve \& bp Nichol (2000). 'The Book as Machine' [1992], in A Book of the Book: Some Works \& Projections About the Book \& Writing, edited by Jerome Rothenberg and Steven Clay, New York: Granary Books, pp. 17-24. 
McGann, Jerome (2001). Radiant Textuality: Literature After the World Wide Web. New York: Palgrave.

McGann, Jerome (2004). 'Marking Texts of Many Dimensions', in Susan Schreibman, Ray Siemens \& John Unsworth, eds., A Companion to Digital Humanities, Oxford: Blackwell, pp. McGann, Jerome (2003). 'Texts in N-Dimensions and Interpretation in a New Key [Discourse and Interpretation in N-Dimensions]', in Text Technology, Vol. 12.2 http://texttechnology.mcmaster.ca/pdf/vol12 2 02.pdf (20 Feb 2010)

McGann, Jerome (1997): "The Rationale of Hypertext" [1995] in Electronic Text. Investigations in Method and Theory, ed. Kathryn Sutherland, Clarendon Press: Oxford, 1997), 19-46.

McGann, Jerome (2002): "Textonics: Literary and Cultural Studies in a Quantum World", at http://www.ciberscopio.net/artigos/tema2/clit 01.html (20 Feb 2010)

Morris, Adalaide and Thomas Swiss, ed., (2006). New Media Poetics: Contexts, Technotexts, and Theories. Cambridge, Mass: MIT Press.

Nelson, Jason (2004). Hymns of the Drowning Swimmer, http://secrettechnology.com/hymns/navigate.html

Nelson, Jason (2007). dimension is night is night (2007) [with Christine Hume] http://www.secrettechnology.com/night/xtine.html

Nelson, Theodor Holm (1993). Literary Machines: The report on, and of, Project Xanadu concerning word processing, electronic publishing, hypertext, thinkertoys, tomorrow's intellectual revolution, and certain other topics including knowledge, education and freedom. Sausalito, CA: Mindful Press /distributed by Eastgate Systems Inc [1st ed. 1981].

Nelson, Theodor Holm (1999). 'Xanalogical Structure, Needed Now More than Ever: Parallel Documents, Deep Links to Content, Deep Versioning and Deep Re-Use', in Computing Surveys, 31 (4), December 1999.

Perloff, Marjorie (2006). 'Screening the Page/ Paging the Screen: Digital Poetics and the Differential Text', in New Media Poetics: Contexts, Technotexts, and Theories, ed. Adalaide Morris and Thomas Swiss, Cambridge, Mass: MIT Press, 143-164.

Peterson, Tim (2006). 'New Media Poetry and Poetics. From Concrete to Codework: Praxis in Networked and Programmable Media', in Leonardo Electronic Almanac, Special Issue: New Media and Poetics, ed. Tim Peterson, Vol 14.5-6 (Sept 2006)

http://leoalmanac.org/journal/Vol 14/lea v14 n05-06/tpeterson.asp (20 Feb 2010)

Portela, Manuel (2000). 'Typographic Translation: The Portuguese Edition of Tristram Shandy', in Joe Bray, Miriam Handley \& Anne Henry (eds.), Ma(r)king the Text: The Presentation of Meaning on the Literary Page, Aldershot: Ashgate, 2000, pp. 291-308.

Portela, Manuel (2006). 'Concrete and Digital Poetics', in Leonardo Electronic Almanac, Special Issue: New Media and Poetics, ed. Tim Peterson, Vol 14.5-6 (Sept 2006) http://leoalmanac.org/journal/Vol 14/lea v14 n05-06/mportela.asp (20 Feb 2010)

Portela, Manuel (2007). 'Significantes em Movimento em Movimento', in Cadernos de Literatura Comparada, № 17, Dezembro de 2007 (Porto: Instituto de Literatura Comparada Margarida Losa): 63-92. 
Portela, Manuel (2009). 'Flash Script Poex: A Recodificação Digital do Poema Experimental', in Cibertextualidades, Volume 3: 43-57. Also available at Po-Ex: Poesia Experimental Portuguesa - Cadernos e Catálogos, Centro de Estudos sobre Texto Informático e Ciberliteratura (CETIC), Universidade Fernando Pessoa, http://poex.net/index.php?option=com content\&task=view\&id=148\&ltemid=31\&lang (20 Feb 2010)

Portela, Manuel (2010). 'The Book as Computer: A Numerical and Topological Analysis of Only Revolutions' [in progress].

Pressman, Jessica (2007). 'Reading the Code between the Words: The Role of Translation in Young-hae Chang Heavy Industries's Nippon', in dichtung digital http://www.brown.edu/Research/dichtung-digital/2007/Pressman/Pressman.htm (20 Feb 2010)

Rothenberg, Jerome and Steven Clay, eds. (2000). A Book of the Book: Some Works \& Projections About the Book \& Writing, edited by, New York: Granary Books.

Seaman, Bill (2007). 'Recombinant Poetics and Related Database Aesthetics', in Database Aesthetics: Art in the Age of Information Overflow, edited by Victoria Vesna, Minneapolis: University of Minnesota Press.

Shillingsburg, Peter L. (2006). From Gutenberg to Google: Electronic Representations of Literary Texts. Cambridge: Cambridge University Press.

Smith, Keith A. (2000) 'The Book As Physical Object' [1994], in A Book of the Book: Some Works \& Projections About the Book \& Writing, edited by Jerome Rothenberg and Steven Clay, New York: Granary Books, pp. 54-70.

Simanowski, Roberto (2010). 'Reading Digital Literature: A Subject Between Media and Method', in Reading Moving Letters: Digital Literature in Research and Teaching. A Handbook., edited by Roberto Simanowski, Jörgen Schäfer, and Peter Gendolla. Bielefeld: transcript Verlag, pp. 15-27.

Sterne, Laurence (1984). The Life and Opinions of Tristram Shandy, Gentleman [1759-1767]. edited by Melvyn and Joan New, Gainesville: University Presses of Florida, [1978]-c1984, Volume II.

Strickland, Stephanie (2006). 'Writing the Virtual: Eleven Dimensions of E-Poetry', Leonardo Electronic Almanac, Special Issue: New Media and Poetics, ed. Tim Peterson, Vol. 14.5-6 (Sept 2006) http://leoalmanac.org/journal/Vol 14/lea v14 n05-06/sstrickland.asp (20 Feb 2010)

Vesna, Victoria (2007). 'Seeing the World in a Grain of Sand: The Database Aesthetics of Everything', in Database Aesthetics: Art in the Age of Information Overflow, edited by Victoria Vesna, Minneapolis: University of Minnesota Press. 
B. Works by Johanna Drucker (1972-2006; digital facsimiles available at Artists' Books Online:

An Online Repository of Facsimiles, Metadata, and Criticism http://www.artistsbooksonline.org/ )

1970s

Dark, The Bat Elf Banquets the Pupae (1972) http://www.artistsbooksonline.org/works/dark.xml

As No Storm or the Any Port Party (1975) http://www.artistsbooksonline.org/works/asno.xml

Twenty-six '76 (1976) http://www.artistsbooksonline.org/works/twen.xml

The Surprise Party Or (1977) http://www.artistsbooksonline.org/works/srpz.xml

Fragile (1977) http://www.artistsbooksonline.org/works/frag.xml

From A to $Z$ (1977) http://www.artistsbooksonline.org/works/atoz.xml

Netherland: [How] So Far (1978) http://www.artistsbooksonline.org/works/hwso.xml

Experience of the Medium (1978) http://www.artistsbooksonline.org/works/expm.xml

Kidz (1979) http://www.artistsbooksonline.org/works/kidz.xml

1980s

Dolls of the Spirit (1980) http://www.artistsbooksonline.org/works/doll.xml

Italy (1980) http://www.artistsbooksonline.org/works/ital.xml

'S crap 'S ample (1980) http://www.artistsbooksonline.org/works/scrp.xml

Jane Goes Out w' the Scouts (1980) http://www.artistsbooksonline.org/works/jane.xml

It Happens Pretty Fast (1982) http://www.artistsbooksonline.org/works/fast.xml

Tongues: a parent language (1982) http://www.artistsbooksonline.org/works/tong.xml

Just As (1983) http://www.artistsbooksonline.org/works/jtas.xml

Against Fiction: Organized Affinities (1983) http://www.artistsbooksonline.org/works/agfi.xml

Spectacle (1984) http://www.artistsbooksonline.org/works/spec.xml

Through Light and the Alphabet (1986) http://www.artistsbooksonline.org/works/ligh.xml

Bookscape (1988) http://www.artistsbooksonline.org/works/bksc.xml

Sample Dialog (1989) http://www.artistsbooksonline.org/works/dial.xml

The Word Made Flesh (1989) http://www.artistsbooksonline.org/works/wmfl.xml

1990s

Simulant Portrait (1990) http://www.artistsbooksonline.org/works/simp.xml

History of the/my Wor(l)d (1990) http://www.artistsbooksonline.org/works/hist.xml

OTHERSPACE: Martian Ty(o)pography (1992) http://www.artistsbooksonline.org/works/mrtn.xml

Deterring Discourse (1993)http://www.artistsbooksonline.org/works/detd.xml

Three Early Fictions (1994) http://www.artistsbooksonline.org/works/earf.xml

Narratology (1994) http://www.artistsbooksonline.org/works/narr.xml

Dark Decade (1995) http://www.artistsbooksonline.org/works/ddec.xml

The Current Line (1996) http://www.artistsbooksonline.org/works/line.xml

Prove Before Laying (1997) http://www.artistsbooksonline.org/works/prov.xml 


\section{0s}

Nightcrawlers on the Web (2000) http://www.artistsbooksonline.org/works/ncwl.xml

Nova Reperta (2000) http://www.artistsbooksonline.org/works/nora.xml

Quantum (2001) http://www.artistsbooksonline.org/works/quan.xml

Emerging Sentience (2001) http://www.artistsbooksonline.org/works/emrg.xml

A Girl's Life (2002) http://www.artistsbooksonline.org/works/grls.xml

Damaged Spring: Pink Noire (2003) http://www.artistsbooksonline.org/works/dspr.xml

Cuba (2005) (with Brad Freeman) http://www.artistsbooksonline.org/works/cuba.xml

Damaged Nature / Salvage Culture (2005) http://www.artistsbooksonline.org/works/dnat.xml

Events: Particle Zoo (2005) http://www.artistsbooksonline.org/works/evns.xml

From Now (2005) http://www.artistsbooksonline.org/works/from.xml

Graphical Investigations (2005) http://www.artistsbooksonline.org/works/grap.xml

Subjective Meteorology (2005) http://www.artistsbooksonline.org/works/subj.xml

Testament of Women (2006) http://www.artistsbooksonline.org/works/tewo.xml 


\section{Works by Jason Nelson (1999-2008)}

2008

Strange Hollows: 15 uses for Micro Black Holes (2008) [with Davin Heckman]

http://www.secrettechnology.com/doomcount/endhere.html

2007

endings eventually end: twenty-five doomsday countdowns (2008) [with Davin Heckman]

http://www.secrettechnology.com/blackholes/collider.html

dimension is night is night (2007) [with Christine Hume]

http://www.secrettechnology.com/night/xtine.html

2006

Pandemic Rooms (2006) http://www.secrettechnology.com/pandemicrooms/

Wheather Visualizer (2006) http://www.secrettechnology.com/weather rss/weather rss.html

The Poetry Cube (2006) http://www.secrettechnology.com/poem cube/poem cube.html

Evil Hypnotizing Mascots (2006) http://www.secrettechnology.com/between/between.html

Between Treacherous Objects (2006) http://www.secrettechnology.com/between/between.html

Alarmingly, these are not lovesick zombies (2006)

http://www.secrettechnology.com/zombie/lovesickzombie6.html

game, game, game, and again game (2006)

http://www.secrettechnology.com/gamegame/gamegame.html

2005

Promiscuous Design (2005) http://www.secrettechnology.com/species/diaone.html

The Bomar Gene (2005) http://www.heliozoa.com/gene/bomargene.htm

Net Behaviour Online Residency (2005) http://www.secrettechnology.com/resident/residency.htm

This is how you will die (2005) http://www.secrettechnology.com/death/deathspin.htm

2004

Dreamphage $n^{\circ} 2$ (2004) http://www.secrettechnology.com/dreamaphage/opening.html

Hymns of the Drowning Swimmer (2004) http://secrettechnology.com/hymns/navigate.html

Uncontrollable Semantics (2004) http://secrettechnology.com/mouse/undirection.html

Speech to Text Poetics (2004) http://www.heliozoa.com/speech/speechtext.html

2003

Dreamphage (2003) http://secrettechnology.com/dreamaphage/introbook.html

Technatomy (2003) http://www.epimone.net/pieces/techna/index.html

Conversation (2003) http://www.heliozoa.com/conversation/conversation.html 
Locomotive and Creatures (2003) http://www.heliozoa.com/new/wave2.html

2002

Plush (2002) http://www.heliozoa.com/plush.html

Panhandle (2002) http://www.heliozoa.com/panhandle.html

this will be the end of you: play 7: genetic code (2002) http://www.heliozoa.com/new/ending7.html

this will be the end of you: play 6: four variable creations (2002)

http://www.heliozoa.com/ending6.html

this will be the end of you: play 4: within within (2002) http://www.heliozoa.com/ending4.html

this will be the end of you: play 3: and the last machine with moving parts (2002)

http://www.heliozoa.com/ending3.html

this will be the end of you: play 1: chemistry or ending 1 (2002)

http://www.heliozoa.com/ending1.html

Superstitious Appliances (2002) http://www.heliozoa.com/superstition.html

\section{0-2001}

Series Poems (2000-2001) http://www.heliozoa.com/resume/series.html

Blur (2000-2001) http://www.heliozoa.com/blur.html

Nine Attempts to Clone a Poem (2000-2001) http://www.heliozoa.com/clone.html

In an Unrelated Sequence Comes (2000-2001) [Cube] http://www.heliozoa.com/resume/cube.html Coalesce and Ennead (2000-2001) http://www.heliozoa.com/resume/frostbite2.html

A Tracing (2000-2001) http://www.heliozoa.com/resume/drag2.html

Another Emotion (2000-2001) http://www.heliozoa.com/resume/color.html

\section{9}

Gorgeous Oaks (1999) http://www.heliozoa.com/resume/trailer/gorgoaks.html

Machine Poems (1999) http://www.heliozoa.com/resume/machine/index.html

(c) Manuel Portela, 2010. All rights reserved. 